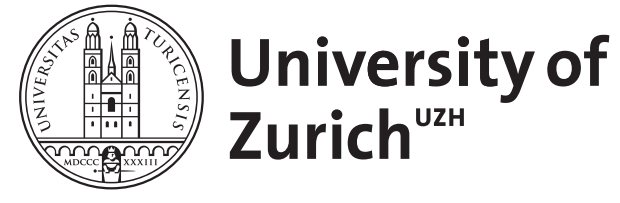

Zurich Open Repository and Archive

University of Zurich

University Library

Strickhofstrasse 39

CH-8057 Zurich

www.zora.uzh.ch

Year: 1985

Weisheitliche Vergewisserung mit Bezug auf den Zionskult: Studien zum 125. Psalm

Beyerlin, Walter

Posted at the Zurich Open Repository and Archive, University of Zurich

ZORA URL: https://doi.org/10.5167/uzh-149705

Monograph

Published Version

Originally published at:

Beyerlin, Walter (1985). Weisheitliche Vergewisserung mit Bezug auf den Zionskult: Studien zum 125.

Psalm. Freiburg, Switzerland / Göttingen, Germany: Universitätsverlag / Vandenhoeck Ruprecht. 


\section{BEYERLIN}

\section{WEISHEITLICHE VERGEWISSERUNG}

MIT BEZUG AUF DEN ZIONSKULT

Studien zum 125. Psalm 


\section{ORBIS BIBLICUS ET ORIENTALIS}

Im Auftrag des Biblischen Instituts der Universität

Freiburg Schweiz

des Seminars für biblische Zeitgeschichte

der Universität Münster i. W.

und der Schweizerischen Gesellschaft

für orientalische Altertumswissenschaft

herausgegeben von

Othmar Keel

unter Mitarbeit von Erich Zenger und Albert de Pury

\section{Zum Autor:}

Jahrgang 1929, o. Professor für Altes Testament von 1963 bis 1973 in Kiel, seither an der Universität zu Münster. Studierte in Tübingen, Göttingen, Basel und Edinburgh. War zunächst im kirchlichen Dienst. Wurde 1956 in Tübingen promoviert auf Grund einer traditionsgeschichtlichen Untersuchung der Prophetie des Micha (FRLANT 72, 1959). Habilitierte sich 1960, gleichfalls in Tübingen, mit der Abhandlung "Herkunft und Geschichte der Sinaitraditionen" (1961). Neben Arbeiten zu Geschichtserzählungen veröffentlichte er Psalmenstudien: zu den Feindpsalmen (FRLANT 99, 1970), zum 126. Psalm (SBS 89, 1978), zum 107. Psalm (BWANT 111, 1980), zum 131. Psalm (SBS 108, 1982) sowie zum 15. Psalm (BThSt 9, 1985). Auch ist er Herausgeber der "Grundrisse zum Alten Testament", im besonderen eines religionsgeschichtlichen Textbuchs (ATD.E 1, 1975). 


\author{
WALTER BEYERLIN
}

\title{
WEISHEITLICHE VERGEWISSERUNG MIT BEZUG AUF DEN ZIONSKULT Studien zum 125. Psalm
}

UNIVERSITÄTSVERLAG FREIBURG SCHWEIZ VANDENHOECK \& RUPRECHT GÖTTINGEN 1985 
CIP-Kurztitelaufnabme der Deutschen Bibliothek

Beyerlin, Walter:

Weisheitliche Vergewisserung mit Bezug auf den Zionskult: Studien zum 125. Psalm/Walter Beyerlin. Freiburg (Schweiz): Universitätsverlag;

Göttingen: Vandenhoeck \& Ruprecht, 1985.

(Orbis biblicus et orientalis; 68)

ISBN 3-7278-0342-8 (Universitätsverl.)

ISBN 3-525-53691-7 (Vandenhoeck \& Ruprecht) NE: GT

(c) 1985 by Universitätsverlag Freiburg Schweiz

Paulusdruckerei Freiburg Schweiz

ISBN 3-7278-0342-8 (Universitätsverlag)

ISBN 3-525-53691-7 (Vandenhoeck \& Ruprecht)

Digitalisat erstellt durch Florian Lippke, Departement

für Biblische Studien, Universität Freiburg Schweiz 
Aubrey und Winifred Johnson

gewidmet 

Inhalt

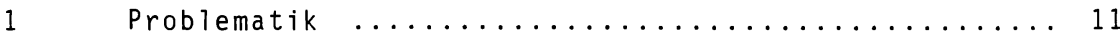

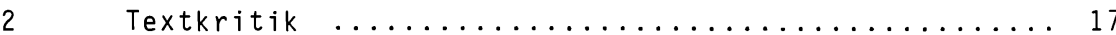

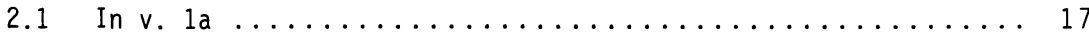

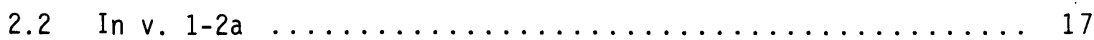

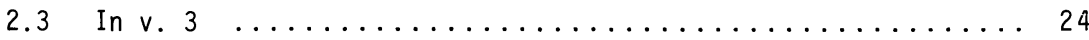

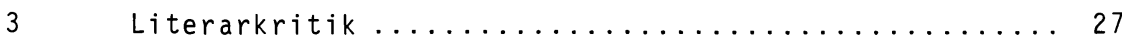

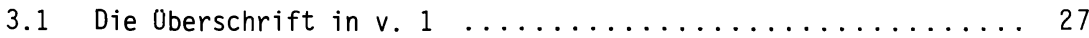

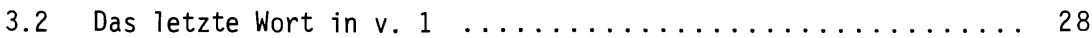

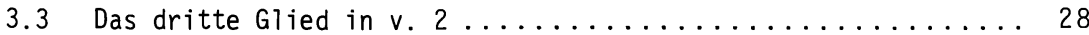

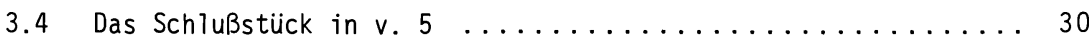

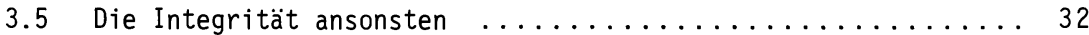

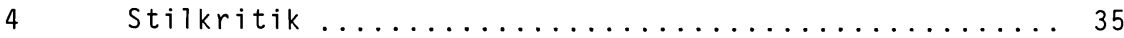

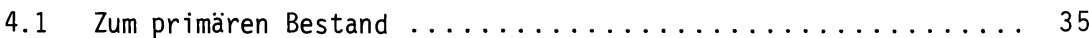

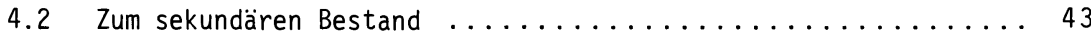

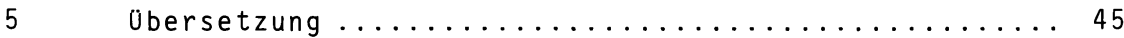

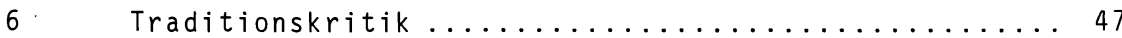

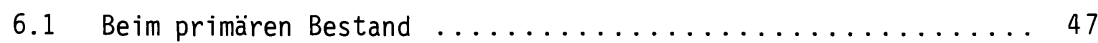

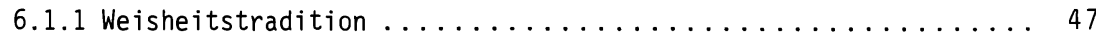

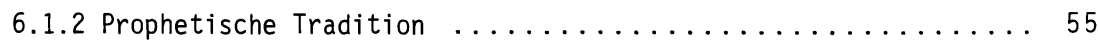

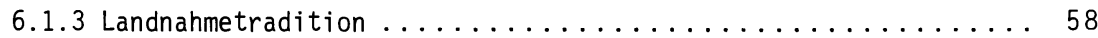

6.1 .4 Jerusalemer Kulttradition, Teil I:
Königstradition

6.1.5 Jerusalemer Kulttradition, Teil II:

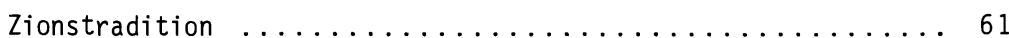

6.1 .6 Rückblick und Auswertungen $\ldots \ldots \ldots \ldots \ldots \ldots \ldots \ldots \ldots \ldots \ldots \ldots \ldots \ldots$

6.2 Beim sekundären Bestand .................. 66

$7 \quad$ Redaktionskritik ..................... 71

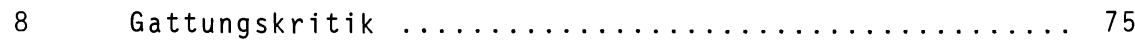

8.1 Die Frage nach dem Sitz im Leben ................ 79

9 Zusammenschau ....................... 81

Abkürzungsverzeichnis ..................... 83

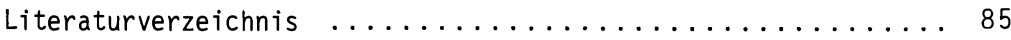

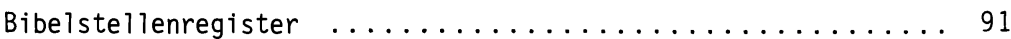


Die vorliegende Recherche gilt einem schwer abzuklärenden Psalm, letzten Endes zugleich einem bemerkenswerten theologie- und kultgeschichtlichen Vorgang der nachexilischen Zeit. - Zum Abschluß gekommen ist, was hier veröffentlicht wird, in den letzten Tagen des Jahres 1984.

Die alsbaldige Publikation in der Reihe Orbis biblicus et orientalis ist deren Herausgebern zu danken, den verehrten Kollegen othmar Keel und Erich Zenger.

Die Ausfertigung des hier abgelichteten Manuskripts oblag meinem Sekretär Bert Alm. Korrektur haben - außer meiner Frau und mir selbst - die Studenten der Theologie Carsten Körber, Christian Peters und Dietrich Schneider gelesen. Letzterer half auch bei der Erstellung der bibliographischen Verzeichnisse und erhob das Stellenregister.

Die hebräischen Textelemente sind nach den Regeln der Zeitschrift für die alttestamentliche Wissenschaft transkribiert.

Muinster, im Januar 1985 Walter Beyerlin 

Problematik

Der Psalm, dem hier nachgegangen wird, ist in ungewöhnlichem Maße schwierig. Sein hebräischer Text läßt so, wie er überkommen ist ${ }^{1}$, gleich eingangs die verschiedensten Satzeinteilungen zu. Mit der Folge divergierenden Sinns. Da können zum einen die Aussagen "er wankt nicht" und "er bleibt auf Dauer" auf den Berg Zion zurückbezogen werden, mit dem die, die auf Jahwe vertrauen, verglichen sind ${ }^{2}$. Da kann zum andern das Satzende nach "Berg Zion" angesetzt und, was folgt, geringfügig anders vokalisiert, zum Nachstehenden geschlagen werden. Dann gilt nicht vom besagten Berg, er wanke nicht, bleibe stets stabil, sondern - vom jošeb jerûsalăim, von dem, der in Jerusalem wohnt ${ }^{3}$. Und zum dritten kann gesplittet werden. So, daß die Wendung "er wankt nicht" zum Zionsberg gehört und der Text ab 1 ecôlam ("auf ewig / auf Dauer") zu den folgenden Gedanken ${ }^{4}$. Mit dem Effekt, daß ausgesagt wird, Jerusalem oder seine Bewohner blieben ewig im Schutze der Berge ringsum ${ }^{5}$. - Es mag überraschen, aber die Möglichkeiten zu gliedern und wiederzugeben sind mit alledem nicht erschöpft ${ }^{6}$. Vor allem der Fragen wegen, die das Wort jšb, im gegebenen Falle, aufwirft. Meint es hier wirklich "wohnen"? Kann es, wie oft unterstellt, überhaupt "bleiben" bedeuten? Warum sollte nicht "sitzen" oder "thronen" in Betracht kommen können? Oberlegungen dieser Art verbreitern das Spektrum der

1 Von der Akzentuierung der Masoreten abgesehen.

2 So die Einteilung bei etlichen Kommentatoren, etwa bei GUNKEL 548, KRAUS 1027, WEISER 521, NOTSCHER 276f, DEISSLER 501.

3 So die Gliederung des Textes bei KALT 464 und BONKAMP 549.

4 Vergleichenswert nebenbei die von BHS verschiedene Zeileneinteilung im Kodex von Aleppo. Sie bedeutet gewiß nicht viel, macht soviel freilich bewußt, daß es nicht angängig ist, sich von der Zeilenanordnung in BHS einfach in Bann schlagen zu lassen.

5 SO BERTHOLET 258 und WUTZ 330.

6 LORETZ 259! 
Textwiedergaben: Jerusalem sitzt, für immer inthronisiert ${ }^{7}$. Oder, noch einmal anders: der zu Jerusalem thront, der dortige Gott, wird nie ins Wanken, nie aus der Fassung geraten ${ }^{8}$. Oder last but not least: Der auf Jahwe vertraut, wird für immer sich niederlassen ${ }^{9}$. Es ist eklatant: eine semantische Frage spielt in die Schwierigkeiten, die im Eingang des Psalmes bestehen, herein.

Die Ubersetzungen der Antike, die "Versionen", spiegeln die Verlegenheit wider. Sie optieren die eine oder andere Art, den Anfang des Psalms zu gliedern. Ja, sie werfen mit abweichenden Lesarten zusätzlich Fragen auf. Auch mit Bezug auf den weiteren Text ${ }^{10}$. Sie sind also offensichtlich auch nicht das sichere Terrain, das Zugänge eröffnen würde.

In literarkritischer Hinsicht verwickeln sich die Dinge noch mehr. Es erscheint nicht bloß bei diesem oder jenem kleineren Stück, etwa der Formel "von nun an und immerdar", 2c, oder dem Schlußwort "Friede über Israel!", 5c, problematisch, ob es zum ursprünglichen Bestand gehört oder hinzugekommen ist ${ }^{11}$. Vielmehr sind sehr wohl auch größere Teile, bisweilen gar mehr als die Hälfte des überkommenen Texts, als Zuwachs eingeschätzt. Verwirrenderweise keineswegs immer dieselben Partien! Einerseits gelten $v$. $1-3 a$ als primärer Bestand, $3 b-5 c$ als sukzessive hinzugeschriebene Glossen ${ }^{12}$. Andererseits wird in 2-3 sowie 5

7 BRIGGS I I 454.

8 So, notorischermaßen einfallsreich, DAHOOD III $214 \mathrm{f}$.

9 In diesem Sinn schließlich EERDMANS $554 \mathrm{f}$.

$10 \mathrm{Ab}$ V. 3.

11 Beim Vermerk "Wallfahrtslied", zu Beginn von v. 1, ist die Nachträglichkeit so anerkannt, daß er hier kaum noch erwähnenswert ist.

12 In der Kommentierung von BRIGGS, II $453 \mathrm{ff}$. 
die Grundschicht angenommen, in 1 und 4 eine Bearbeitungsschicht ${ }^{13}$. Drittens wird das Primäre, der Kern, in kühn veränderndem Eingriff, in Wendungen von $v$. 1 eruiert, überdies in $3 a$ und 4-5b; alles übrige, wahrlich nicht wenig, ist Glossierung und Erweiterung, Belastung des ursprünglichen "Lieds" 14. Man fragt sich nach allem, was überhaupt am vorliegenden Psalm noch niemals als nachträglich in Verdacht geraten ist. Etwa einzig das Wort wider das gottlose Zepter, $3 a$, und der Wunsch ${ }^{15}$ im abschließenden Vers? Wen irritierte so etwas nicht? Wen irritierte nicht vollends, daß noch immer, ja, neuerdings mehr denn je, die Meinungen divergieren? Wer kann sich dem Eindruck entziehen, der Text sei literarkritisch gesehen so schwierig wie unter dem Gesichtspunkt der Gliederung? - Wer könnte bei alldem verkennen, in welchem Maße die Erfassung des Sinns, des primären und sekundären, je von der literarkritischen Einschätzung abhängig ist? Was Wunder, daß, wenn der kleine Psalm so weitgehend aufgeteilt wird, es schwieriger werden muß, überhaupt noch gedanklich abgerundete Zusammenhänge erkennen zu können. Was Wunder, daß es da zu Fehlanzeigen kommt. Mit Bezug auf die behauptete Grundschicht zu der: Es sei "kaum wahrscheinlich", daß diese "einmal eine selbständige und vollständige Einheit gebildet haben sollte". Man habe "den Eindruck, es handle sich hier um einige unfertige Formulierungen, vielleicht als Gedächtnisstütze für mündlichen Vortrag."16

Fehlanzeige bezeichnenderweise zugleich beim vermeintlich sekundären Bestand: "Auch die Bearbeitung bringt keine Linie in den Text. Er ist und bleibt ein Torso"17. Reizen nicht diese Anschauungen - zusammen mit dem Dissens zwischen den literar-

13 So Erwägungen und Aufstellungen bei SEYBOLD, Die Redaktion 253, Die Wallfahrtspsalmen 49.62.90.

14 "Textologisches" Fazit bei LORETZ, II $258 \mathrm{ff}$.

15 Abzüglich "Jahwe".

16 SEYBOLD, Die Wallfahrtspsalmen $49 / 50$.

17 SEYBOLD, Die Wallfahrtspsalmen 50. 
kritischen Urteilen der letzten Zeit ${ }^{18}$ - dazu, noch einmal von Grund auf neu nachzuforschen?

Prekär ist, daß auch mit den sonstigen exegetischen Methoden tragfähigerer Boden kaum unter die Füße gebracht worden ist. Weder mit der Stil- noch etwa mit der Gattungskritik. Unter dem ersteren der beiden genannten Aspekte ist es zu einer umfassenderen Untersuchung noch gar nicht gekommen. Und vereinzelte Bemerkungen nützen nicht viel ${ }^{19}$. Thesen wie die erscheinen der uberprüfung bedürftig, da seien "fast gar keine festen Strukturen" erkennbar ${ }^{20}$ und "in den ungelenken und schwerfälligen Formulierungen sprechen sich Menschen aus, die sich schwer tun im Umgang mit dem Wort"21. Träfen diese Aufstellungen zu, so bliebe allerdings auch wenig Grund zu der Hoffnung, stilkritische Befunde könnten vielleicht den einen oder anderen Anhalt gewähren. - Was unter dem Aspekt der anderen Methode, also gattungskritisch, zum Psalmtext vorgebracht wurde, hilft ebensowenig voran. Wie könnte auch verstehen helfen, wenn immer wieder gesagt wird, er gehöre "im weiteren Sinne" zur Gattung der Volksklagelieder? Im weiteren Sinne - weil die klage in inm verstummt sei, Vertrauen im Vordergrund stehe. Er sei drum, genauer genommen, Vertrauensiied des Volkes ${ }^{22}$. Was nützt eine solche Umschreibung? Tritt sie nicht, mit dem Pathos der Gattungsbestimmung, den offenkundigen Umstand breit, daß im Eingang des Psalms das Vertrauensmotiverscheint? Eine wirkliche den Text umgreifende und prägende Gattung ist so doch nicht

18 Man vgl. SEYBOLD, Die Wallfahrtspsalmen mit LORETZ, I I $258 \mathrm{ff}$ oder VAN DER PLOEG, II $366 \mathrm{ff}$ !

19 Vollends nicht die unter dem relativ häufig berührten Gesichtspunkt rhythmische Gliederung, zumal ein Konsens noch nicht sichtbar wird. Man vgl. nur etwa GUNKEL, 550, mit VAN DER PLOEG, II 366.

20 SEYBOLD, Die Wallfahrtspsalmen 49.

21 SEYBOLD, Die Wallfahrtspsalmen 4l. Ahnlich, anfangs des Jahrhunderts, DUHM 436.

22 GUNKEL 548. In seinem Gefolge andere. Man vgl. z.B. TAYLOR 660 oder auch VAN DER PLOEG II 365. 
festgestellt! Nichts, was Schlüsse zu ziehen erlaubte, etwa - was hilfreich wäre - auf einen Sitz im Leben ${ }^{23}$. Zudem, mit jener Art von Gattungsumschreibung konkurrieren auch allerlei andere, die kaum weniger fragwürdig sind: etwa "prayer liturgy"24 oder "Gattung der geistiichen Lieder" 25 oder kaum klassifizierbares individuelles Gebet ${ }^{26}$. Daneben sind Versuche beachtlich, behelfsweise - differenziert und komplex - zu umschreiben ${ }^{27}$. Unverkennbar nach allem, daß unser Psalm, so wie er beschaffen ist, gattungskritisch sehr schwer zu nehmen und zu erschließen ist $\mathrm{t}^{28}$.

Inm gemäßer ist offenkundig die Methode der Traditionskritik ${ }^{29}$, - die "kritisch" unterscheidende Erhebung, welche Traditionen, welche geprägten geistigen, vorstellungsmäßige Welten ("Rückräume"), den Psalmisten bei der Abfassung seines Texts bewegt und beeinflußt haben. Indessen, gerade diese so gemäße und aufschlußreiche Methode ist beim vorliegenden Psalm noch nirgends so recht zum Tragen gekommen. Sie bleibt, auch im besten Falle, in Ansätzen stecken, erschöpft sich zumeist in Hinweisen auf diesen oder jenen vermeintlichen oder wirklichen Berührungspunkt mit anderem alttestamentichen Textgut ${ }^{30}$, ist bis dato

23 Ein Gesichtspunkt, ganz nebenbei gesagt, der oft gar nicht angesprochen wird!

24 LESLIE 125. Eine Einschätzung, die auf einen kultischen "Sitz" abzielt und - literarkritische Fragen verdrängt!

25 STAERK 213

26 SEYBOLD, Die Wallfahrtspsalmen 19.55.

27 Anerkennenswert DEISSLER 502 sowie KRAUS 1028.

28 ANDERSON, 861 , spricht diese Schwierigkeit zutreffend an.

29 Zu deren Erläuterung etwa BEYERLIN, Wider die Hybris $71 \mathrm{f}$.

30 U.a. ins Auge gefaßt sind Gen 49,10; Jes 28,16 ; die tritojesajanischen Stellen 57,$13 ; 60,21 ; 65,9$; auch Mi 7,7ff; andererseits, sei es ganz, sei es versweise, Ps $1 ; 15 ; 34$; $37 ; 45 ; 46 ; 73$ und 119, ferner Spr 2,13ff und Sir 32,23, vereinzelt auch summarischer, weitergreifend Elemente der Lehrdichtung, die Weisheits- und die Zionstradition. Siehe PRESS, Der zeitgeschichtliche Hintergrund 403.404 und 413 , 
weder umfassend noch tiefschürfend und konsequent genug durchgeführt. - Wie aber sollen, so lange der Stand der Dinge so ist, Movens und Sinn unseres Psalms, gegebenenfalls seiner literarischen Schichten, zureichend erfaßt werden können? Wie sollen so wichtige Gesichtspunkte wie Urheberschaft und Entstehungszeit ${ }^{31}$ ohne traditionskritische, traditionsgeschichtliche Grundlegung in den Griff gebracht werden können?

Nach allem genug! Die Problematik, die das Verständnis unseres Psalmes hindert, ist zwar nicht enzyklopädisch, aber in den wichtigsten Komponenten, die zusammenwirken, umschrieben. Ist nicht längstens klar, daß es hier, auch in diesem Fall, gerechtfertigt ist, von Grund auf neu zu sondieren, daß es einer wohlangelegten Folge von Studien bedarf, um das Knäuel der Probleme aufzulösen ${ }^{32}$ ?

ansonsten die Psalmenkommentare, namentlich GUNKEL $548 \mathrm{f}$, DEISSLER 502 und, am meisten der Hervorhebung wert, KRAUS 1028.

31 Gerade auch etwa im letzten Punkt gehen die Meinungen weit auseinander. Man vgl. beispielsweise H. SCHMIDT 226 und EERDMANS 555 (vorexilisch datierend) mit PRESS, Der zeitgeschichtliche Hintergrund (Schlußphase des babylonischen Exils) mit der Mehrzahl der übrigen Kommentatoren (abhebend auf die verschiedenen Abschnitte der nachexilischen Zeit)!

32 Der Kürze halber sei es dem Verfasser erlassen, die Folge der Untersuchungsschritte im Vorwege plausibel zu machen. Einiges versteht sich ohnehin ganz von selbst. So gewiß dies, daß nicht anders als textkritisch eingesetzt werden kann. 
Textkritik

Wie hat der hebräische Text unseres Psalms, als er zu Ende gegestaltet war, ausgesehen, einschließlich etwaiger Zusätze ${ }^{33}$ ?

2.1

In $v .1 a$

Es leidet hier keinen Zweifel, daß der ursprüngliche Text "die, die auf Jahwe vertrauen" dem Berge Zion verglichen, kehăr-sijjôn prädiziert hat. Es ist, entgegen der Lesart der versio Syriaca und spätmittelalterlicher hebräischer Handschriften, nicht seine Meinung gewesen, für die, die auf Jahwe vertrauen, sei es zugleich von Belang, daß sie behăr-sijjôn, auf besagtem Berge seien und ihr Vertrauen auch auf diesen erstreckten. Der Konsonant b, der bei "auf" vorausgesetzt wird, ist aus dem in der Quadratschrift ähnlichen k hervorgegangen ${ }^{34}$. Die Vergleichspartikel, die mit diesem Konsonanten angezeigt wird, ist weitaus besser als b bezeugt ${ }^{35}$. Unumstößlich nach allem, daß eingangs des Psalms von denen die Rede ist, die ausschließlich auf Jahwe, nicht zugleich und im Zusammenhang damit auf Zion, den von ihm geheiligten Berg, vertrauen.

\section{2}

In $v .1-2 a$

Es klang bereits an: die Septuaginta nimmt nach dem Eröffnungssatz, der die Gottvertrauenden mit dem Zion vergleicht, einen trennenden Einschnitt an, läßt mit der dann folgenden Wendung "er wankt nicht in Ewigkeit" den nächsten Satz einsetzen und begreift als dessen Subjekt nicht etwa das zu Beginn von v. 2

33 Zur Abgrenzung gegenüber der Literarkritik: BARTH / STECK, Exegese, $1980,23 \mathrm{f}$; WURTHWEIN, Der Text, 41973, $102 \mathrm{f}$.

34 WURTHWEIN, Der Text, ${ }^{4} 1973,104.215$, Abb. 48!

35 Nicht allein durch die maßgebenden masoretischen Codices, sondern auch durch llQPsa sowie Septuaginta, Vulgata u.a.m. 
zur Sprache gebrachte Jerusalem, sondern denjenigen, der es be-

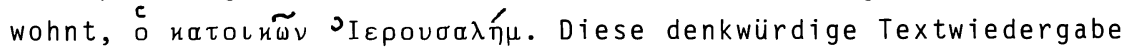
setzt hierbei, evidentermaßen, eine vom masoretischen Wortlaut abweichende Aussprache und Vokalisation der Konsonanten jšb voraus. Partizipiales jošeb. Nicht imperfektisch ješeb, wie hernach, Jahrhunderte später, von den Masoreten punktiert. Die Septuaginta weicht nota bene, nicht im mindesten vom hebräischen Konsonantentext ab, bezeugt diesen wie die Masoreten. Sie gibt aber der Oberzeugung Ausdruck, das konsonantische jšb wolle partizipial gelesen und aufgefaßt werden; es meine den, genauer gesagt, jedweden, der Jerusalem bewohnt, sinngemäß kollektiv, die Bewohnerschaft Jerusalems.

Es ist nicht zwingend, anzunehmen, diese oberzeugung der Septuaginta stehe und falle mit der Gliederung in Sätzen, welche sie für angebracht hält. Eher ist für möglich zu halten, daß sie mit einer bestimmten Zuordnung zusammenhängt. Wie es scheint, mit der zum folgenden Wort, mit "Jerusalem" eingangs des Verses 2. Im übrigen steht zu vermuten, daß die obersetzer ins Griechische einer Aussprachetradition gefolgt sind. Die maßgebende Frage dürte sein, ob diese der Endgestaltung des Textes entspricht. Zu ihrer Entscheidung verhilft nach Lage der Dinge eher die Innere als die Außere Textkritik ${ }^{36}$. Insonderheit die Oberlegung, was jšb im alttestamentlichen Hebräisch überhaupt bedeutet haben kann.

36 Zumal ein wertvoller Zeuge, die Handschrift 1lQPsa , in der anstehenden Frage nicht sicher zu verrechnen ist. Zwar liebt er scriptio plena und den Gebrauch der mater lectionis, läßt insofern auch erwarten, er zeige das entscheidende o im Falle partizipialer Formung an. Indes, die so wichtige Psalmenhandschrift von Qumran weist just an der fraglichen Stelle eine Lücke auf. Das nachfolgende Wörtchen $1 \mathrm{w}$, das eindeutig masc. ist, erlaubt - wegen des seltsam parallelen Befunds bei der Bezeugung von 122,3 in der nämlichen Handschrift 11QPs - nicht ohne weiteres den Rückschluß auf ein partizipiales jwšb, das ja ganz ohne Frage ebenso masc. sein würde. Man vgl. hier SANDERS, The Psalms Scroll 24.25! Mag ja sein, daß dieser Zeuge mit der Septuaginta (und dem Psalterium Gallicanum) zusammen ("qui habitat in Hierusalem") in ein und dieselbe Wagschale gehört. Erweisbar ist es indessen nicht. 
Semantisch ist zu beachten, daß das Wort in alttestamenticher Zeit nicht so einfach, wie von vielen unterstellt" 37 , "bleiben" gemeint haben kann. Lexikalisch ist offenbar ${ }^{38}$, daß es sich, im biblischen Hebräisch, von den Bedeutungen "sich setzen, sitzen" ${ }^{39}$, sitzen bleiben, wohnen, bewohnen" nicht löst, - daß es nie, wie in nachbiblischer Zeit 40 , vom "Sitzen" und "Wohnen" abstrahiert, die Bedeutung "ruhig sein" annimmt. Es ist demgemäß klar, daß die Masoreten, die erst nachbiblisch frühmittelalterlich tätig waren, keine Schwierigkeiten gehabt haben konnten, vom Zionsberg gesagt sein zu lassen, "er wankt nicht", (dann relativ starker Trenner, und die folgenden beiden Wörter miteinander durch Verbinder verklammert) "er ist auf Dauer ruhig", "bleibt" unbewegt in diesem Sinn. Andererseits ist ebenso klar oder sollte es wenigstens sein, daß vor dem Ende der biblischalttestamentlichen Zeit das uns vorliegende jšb die Bedeutungs momente "sich setzen, sitzen, wohnen, bewohnen" nicht abgestreift haben konnte. Selbst an den ganz wenigen Stellen, Gen 22,5 und 24,55, wo jšb "dableiben" im Gegensatz zu hlk, zu "gehen, weggehen" meint, ist "sitzenbleiben" mit inbegriffen. Dieser Gesamtsachverhalt muß Zweifel wecken, ob ein so verstandenes Verb jšb auf jenen Berg überhaupt bezogen gewesen sein konnte. Gewiß ist nicht auszuschließen, daß dieser in alttestamentlicher Zeit personhaft vorgestellt war und ihm entsprechend personhaftes Tun und Lassen zugeschrieben worden sein konnte ${ }^{41}$. Ist indessen plausibel, daß von ihm ausgesagt gewesen sein sollte, er bleibe auf Dauer "dasitzen" oder gar "wohnen" 42 ?

37 Von Kommentatoren neuerer Zeit, aber auch schon von Obersetzern der Antike (etwa denen der versio Syriaca), ja, last but not least von den Masoreten, die den Codex Leningradensis punktiert (vokalisiert und akzentuiert) haben. Näheres hierzu im Folgenden!

38 BAUMGARTNER, Hebräisches und aramäisches Lexikon, 31974, 424.

39 Je nach dem Kontext "den Thron besteigen, thronen".

40 DALMAN, Aramäisch-neuhebräisches Handwörterbuch 188.

41 Die Stellen Ps 68,$17 ; 98,8 ; 114,4.6$; Jes 44,$23 ; 49,13 ; 54,10$ und 55,12 dokumentieren diese Möglichkeit!

42 EERDMANS 555 ! 
Bleibt man in diesem Punkte genau, so schwindet 43 die Neigung, jšb auf besagten Berg zurückzubeziehen. Versucht man mit den im alttestamentlichen Hebräisch gesicherten Bedeutungen "sich setzen, sitzen, sitzen bleiben, wohnen, bewohnen" zurechtzukommen, so senkt sich die Wagschale mit Zwangsläufigkeit ${ }^{44}$ auf der Seite der griechischen Lesart ${ }^{45}$ : Im Rahmen des in alttestamentlicher Zeit semantisch tatsächlich Möglichen hat es mehr für sich, jy̌b in einer jener wohldokumentierten Bedeutungen - "wohnen, bewohnen" - mit der anschließend erwähnten Stadt im Zusammenhang stehen zu lassen. Es ist, nach der letzten Gestaltung des ursprünglichen Texts, vom Bewohnen Jerusalems die Rede. Und da es, abgetrennt vom voraufgehenden Text, eines neuen Subjektes bedarf, ist dasselbe, bei der überkommenen Wörterverbindung, schwerlich irgendwo anders zu finden als in dem Wort jub selbst. Es muß zunächst, so wie von der Septuaginta vorausgesetzt, jošeb jerû̌salăim geheißen haben: "der, der in Jerusalem wohnt", "jedweder, der Jerusalem bewohnt" oder, deutlicher kollektiv, "Bewohnerschaft Jerusalems" 46 .

Allerdings, die offenkundige Parallelität zwischen den Vershälften $2 a$ und $2 b$ weckt alsobald andere Zweifel: Die nämlich, ob in dem intendierten Vergleich, der wahrgenommenen Entsprechung "Bewohnerschaft" Platz gehabt hat. Spricht nicht alles dafür, daß Jerusalem selbst und als solches, die vor Augen liegende bergumgebene Stadt - und nicht, komplizierter und unanschaulicher, "die Bewohnerschaft Jerusalems" - mit dem von seinem Gott umhegten Volk verglichen worden ist? Auch liegt die Annahme am nächsten, jenes $1 \mathrm{~h}$ am Ende des Verses 2 a sei von Hause aus auf das feminine Wort Jerusalem zurückbezogen gewesen

43 Trotz BRIGGS II 454 sowie MANNATI / DE SOLMS 145.

44 Auch nicht durch DAHOOD III 214.215 im Ernste aufgehalten.

45 Bemerkenswert nebenbei, wie sich der skizzierte Sachverhalt bei DUHM 434 Geltung verschafft! Im ganzen kann man seinem Lösungsversuch, weil er eine Textänderung einbegreift, nicht folgen.

46 Gen 34,30 belegt, daß das partizipiale jošeb sehr wohl kollektiv die Bewohnerschaft eines bestimmten Bereiches gemeint haben kann. 
und nicht auf das Masculinum jošeb jêû̌salăim. Es steht, so möchte man meinen, tausend gegen eins, daß primär Jerusalem, Jerusalem selbst und nicht so hervorgehoben dessen Bewohnerschaft, ob seiner geschützten Lage vergleichsweise apostrophiert worden ist. Es sieht danach aus, als habe hernach, sekundär, "des Gedankens Blässe" gefunden, komparabel und kompatibel sei mit Jahwes Volk nicht so sehr Jerusalem; vielmehr seine Bewohnerschaft. Mutet dies nicht - ob der Kleinlichkeit des Bestrebens, den Vergleich zu perfektionieren - glossenhaft an? Wem könnte solches so angelegen gewesen sein, daß er drum, die Natur des Vergleichs verkennend, $v$. $2 a$ zu zerdehnen und seine grammatische Stimmigkeit zu strapazieren in Kauf $n a h m{ }^{47}$ ? Dies kann kaum ein anderer als ein Späterer, ein Glossator gewesen sein. In einem Akt witzlos perfektionierender Glossierung ist vor jêû̌salăim ein partizipial gemeintes jšb eingetragen worden. Literarkritisch gesehen ein Zusatz. Textkritisch betrachtet jedoch ein Bestandteil des ursprünglichen Texts in seiner Letztgestalt.

Die Interpolation von jǔb hat vielfältig Verwirrung gestiftet! Sie hat zu der Auffassung geführt, in jošeb jêrǔsalăim, der Bewohnerschaft Jerusalems, sei das Subjekt zu dem Prädikat "wird auf Dauer nicht wanken" zu erblicken. Die Septuaginta - und im Anschluß an sie auch andere - sind zu der Meinung gelangt, so

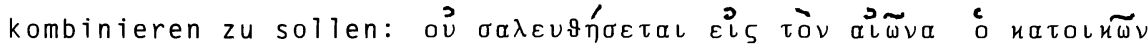

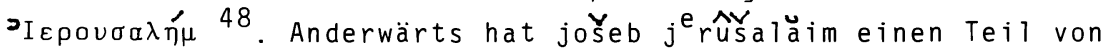
v. Ib angezogen und vom voraufgehenden Text separiert ${ }^{49}$.

47 Denn, wje berejts angedeutet, hätte das maskuline jošeb jerušalăim im Rückbezug eigentlich lw (statt des bezeugten ih) verlangt. Wobei allerdings hinzuzubemerken ist, daß auch 1 h einer o-Vokalisierung Raum zu geben vermag. Man vg 1. MEYER, Hebräische Grammatik, I, 1966, 50 und etwa auch WUTZ 330.331 !

48 Zu den Nachwirkungen dieses Textverständnisses siehe etwa noch einmal KALT 464; BONKAMP 549! Man vgl. hier und im Folgenden ergänzend das zu Beginn von Ziffer 1 Referierte!

49 Man vgl. beispielshalber WUTZ $330 \mathrm{f}$ ! 
Schließlich ist der Versuch zu verzeichnen, von dem wenig überzeugenden Bedeutungsmoment "Bewohnerschaft" wieder loszukommen und die Wendung in einem anderen Sinn zu verkraften: in dem des "Jerusalem-Throners" Jahwe 50 . Ein Versuch von kaum größerer oberzeugungskraft!

Andererseits haben begreifliche Bedenken gegenüber einem partizipialen jšb, das Vergleich und Parallelelität in v. 2 verschlimmbessert, den Ausweg beschreiten lassen, jšb imperfektisch zu fassen und ins Gefüge des Gedankens v. 1b einzupassen. So zurechtzukommen erschien in der Zeit der Masoreten möglich. Vermochte doch jenes Verbum inzwischen "ruhig sein" zu bedeuten. Gleichwohl führte der vermeintlich gangbare Ausweg stracks zu Unannehmlichkeiten. Er bescherte die Oberdehnung des Verses $1 \mathrm{~b}$. Und er spaltete, um Zweigliedrigkeit zu erzeugen, $10^{3}$-jimmôt $1^{\text {ecôlam }}{ }^{51}$, was doch ganz offensichtlich als Formel zu bewerten und unzertrennlich ist ${ }^{52}$. Folgewirkungen, die zwar die Masoreten nicht störten, die aber doch dem, der formkritisch geschult zurückblickt, bedenklich erscheinen müssen. Was Wunder, daß sich dann nachgerade an der Gestalt des masoretischen Textes wiederholt Versuche entzündeten, durch Änderungen, "Emendationen" 53 , oder abweichende Einteilung 54 Unannehmliches abzubauen! Versuche, muß man wohl sagen, die ihrerseits fragwürdig sind!

Nach allem ist offenbar, daß alle überkommenen Bezeugungen die masoretische so sehr wie die griechische und beide vorne-

50 DAHOOD III $214 \mathrm{f}$.

51 Man beachte die masoretische Akzentsetzung!

52 Man vgl. in dieser Hinsicht Ps 15,$5 ; 30,7 ; 112,6$ sowie Spr 10,30! Siehe nicht zuletzt CULLEY, Oral Formulaic Language 57 , Formel $\mathrm{Nr}$. 46 !

53 DUHM $434 f$; LORETZ II $258 f$ ! Beide ändern, um ein mit ješbb verträglicheres Subjekt zu bekommen, den pluralischen Anfang des Psalms "Die, die Jahwe vertrauen" in den Singular "Der, der Jahwe vertraut". Ebendieser soll es nun sein, der "wohnt"!

54 Abweichend von der, die die masoretische Akzentuierung bewirkt. Siehe BRIGGS II 454; BERTHOLET 258! 
weg! - in sich problematisch sind. Es ist kaum weniger klar, was hierfür ursächlich ist: Die ungeschickte und sachlich überflüssige Glosse jošeb, die zur Perfektionierung des Vergleichs von v. 2 jerûsalăim vorangestellt worden ist. Sie ist, begreiflicherweise, bald unverständich geworden und hat so in den verschiedenen Zweigen der Textüberlieferung Bemühungen angestoßen, die darauf gerichtet sind, das glossenhafte Wort $z u$ "verdauen". So verschieden auch die sich so ergebenden Fassungen des Textes sind, so setzen sie doch, direkt oder indirekt, dieselben hebräischen Konsonanten - jšb - voraus. Diese Einhelligkeit verwehrt es, sie textkritisch auszumerzen. Sie sind in nicht zu bestreitender Weise Teil der abschließenden literarischen Gestaltung des Psalms. Sprachgeschichtlich-semantische Besinnung legt klar, daß die Septuaginta, nicht etwa der Masoretische Text, Aussprache, Sinn und Bezug von jy̌b dem Urtext gemäß bezeugt. Gemeint war ursprünglich: "Die Bewohnerschaft Jerusalems 55 - Berge umhegen sie, und Jahwe umhegt (genauso) sein Volk."

Zusammen mit der textkritischen Frage klärt sich zugleich auch die, wie der Text gegliedert sein will: 10 $0^{2}$-jimmôt $1^{e c \hat{o}}$ am "er wankt nie" ist nicht zu zertrennen und hat nichts mit jüb zu tun, gehört vielmehr, entgegen der Auffassung der Griechischen Bibel, im Einklang jedoch mit der Handschrift 11QPs ${ }^{256}$, zum voraufgehenden Text, am unmittelbarsten zum "Zionsberg". So schält sich am Ende dieser sichtich recht wichtigen textkritischen Erörterung heraus:

1a: "Die Jahwe vertrauen, sind wie der Zionsberg:

1b: Er wankt nie.

2a: Die Bewohnerschaft Jerusalems Berge umhegen sie.

2 b Ebenso umhegt Jahwe sein Volk."

55 Siehe dazu noch einmal Anm. 46!

$56 \mathrm{Vgl}$. die relativische Anbindung von 1 b an la in ihr! 
2.3

In $v .3$

Weit weniger aufwendig ist die Klärung der hier dringlichen Fragen ${ }^{57}$. - Eine von ihnen ${ }^{58}$ läuft im wesentlichen darauf hinaus, ob im 3. Vers vom "Zepter des Frevels 59 " oder "des Frevlers $59 "$ die Rede ist. Im letzteren Falle wäre die Person, die das Unrechtsregiment vertritt, mit zur Sprache gebracht; im ersteren Falle nicht. - Die zweite Lesart (harašac "des Frevlers") ist weniger gewichtig bezeugt. Sie hat lediglich einige masoretische Handschriften nachgeordneten Rangs hinter sich; ansonsten das rapavónou der übersetzung des symmachus (vom ausgehenden 2. Jh. n. Chr.) 60 . ob indessen die Septuaginta mit $\tau \widetilde{\omega} \nu$ å $\mu \rho \tau \omega \lambda \widetilde{\omega} \nu$ (gen.plur. "der Sünder") für dieselbe Lesart (harašac "des Frevlers") in Anspruch zu nehmen ist, scheint keineswegs sicher zu sein. Gesetzt den Fall, ihre übersetzer wären, freier übertragend, bestrebt gewesen, das abstrakt Formulierte personenbezogen greifbar zu machen, vielleicht auch, um den Gerechten von $v$. 3a die Frevler entsprechen zu lassen, so könnten sie bei alledem durchaus von haraešc ausgegangen sein, der Lesart mithin, die der Masoretische Text (mehrheitlich und in den maßgebenden Handschriften) bezeugt. Somit sollte dahingestellt bleiben, auf welcher Seite, für welche der beiden Fassungen, die Septuaginta zu verrechnen ist. Im übrigen versteht sich von selbst: Das Psalterium Gallicanum ist (mit "peccatorum") einfach von der Septuaginta abhängig. Die versio Syriaca ist es im vorliegenden Falle - wie überhaupt an vielen Stellen 61 - wohl auch. Ergo steht alles in allem nicht viel und nichts von Gewicht hinter der Lesart harašac, "des Frevlers". -

$573^{a}$ im Apparat von BHS gehört gewiß nicht zu ihnen; k今 hat als ursprünglich zu gelten.

$583^{\mathrm{C}}$ in BHS.

59 VAN LEEUWEN, $r Y^{C}$, in: THAT II, $1976,813 \mathrm{ff}$.

60 Nach der Ausgabe von FIELD, Origenis Hexaplorum II 283 und der dortigen Anmerkung, die die Syrohexaplaris anführt.

61 WURTHWEIN, Der Text, ${ }^{4} 1973,87 \mathrm{f}$. 
Andererseits ist in die Wagschale zu werfen, daß der Ausdruck Sebaet haraešac , "Zepter des Frevels", nichts Verdächtiges an sich hat ${ }^{62}$. Anderwärts ist in echter Entsprechung von Yebaet mî̌̌r die Rede, gar in ausdrücklichem Kontraste zu raě̌ac, $\dot{P}_{s}$ 45,7.8. Warum sollte dann der uns überkommene Ausdruck änderungsbedürftig sein? Ja, in Ez 7,11 wird, in noch weitergehender Entsprechung, măttē-raešc formuliert, "Stab des Frevels". Warum sollte dann, allës in allem gerechnet, unsere Lesart šebaet haraešac nicht als ursprünglich zu belassen sein? Der Urtext dürte, mehr bild-und symbol-als personenbezogen, vom "Zepter des Frevels" gesprochen haben!

Eine weitere Frage ${ }^{63}$ beim selben Vers, im nämlichen Zusammenhang, betrifft das Verb, das zum Ausdruck bringt, was mit dem Zepter geschehen s011. Die Frage läuft darauf hinaus, ob das "Zepter des Frevels" Subjekt des Geschehens im grammatischen Sinne ist oder ob es, anders ins Auge gefaßt, das objekt einer Handlung bildet, deren Subjekt die Gottheit ist. Um das Kaliber des Textproblems nicht größer als nötig erscheinen zu lassen, ist sogleich hinzuzubemerken, die Differenz sei in ihrem Kerne nicht groß. Sie besteht, bei Lichte besehen, darin, daß Jahwe, der nach alttestamentichem Verständnis alles geschichtliche Geschehen bewirkt, im ersteren Falle hintergründig unerwähnt bleibt, im letzteren Falle hingegen enthüllt und ausdrücklich zur Sprache kommt. In der letzteren Fassung bietet die Septuaginta den Text dar. Sie formuliert, rückbezogen auf kúpıos,

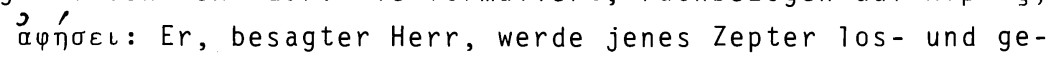
währen lassen, werde es ruhen lassen. Die Ubersetzer setzen das Hiph ${ }^{C} i l$ von nwh, jnjh voraus. Demgegenüber hat der Masoretische Text, graphisch nur eine Winzigkeit anders, das Qal von derselben Wurzel, also jnwh. Er bringt so - im erstgenannten Sinne - zum Ausdruck, das Żepter des Frevels bleibe nicht ruhen. Es steht außer Frage: letztere Fassung ist breiter und

62 MEYER, Hebräische Grammatik II, 1969, 45/46.

$633^{\text {b }}$ im Apparat von BHS. 
gewichtiger bezeugt. Die Septuaginta steht mit ihrer Variante allein da ${ }^{64}$. Selbst symmachus tritt ihr nicht bei, bleibt faktisch aufseiten der Lesart, welche dann die Masoreten vertreten $^{65}$. Hervorzuheben ist noch, daß auch die gar ältere hebräische Handschrift $11 Q P s^{a}$ jnwh, nicht kausatives jnjh, aufweist ${ }^{66}$. Ergo ist klar, daß die Verbform im Qal Rückhalt in mehreren Zweigen der Textüberlieferung hat. - Zieht man mit in Betracht, daß bei Zusagen für die Zukunft die Möglichkeit bestens belegt ist, den geschichtswirkenden Gott gleichwohl nicht grammatisches Subjekt sein zu lassen, vielmehr das, was sein oder nicht sein sol1 $17^{67}$, so hat die Annahme am meisten für sich, jnwh, nicht jnjh, sei ursprünglich. Mithin wird v. 3 im Urtext wie folgt angehoben haben: $k j l^{2}$ jnwh šbt $h r \hat{s}^{c} \ldots$ -

"Fürwahr, nicht wird (lasten) bleiben das Zepter des Frevels ..."

64 Abgesehen natürlich vom Psalterium Gallicanum, welches von ihr abhängig ist.

65 Dazu noch einmal FIELD (Hg.), Origenis Hexaplorum II 283.

66 SANDERS, The Psalms Scroll 25; zur Frage der zeitlichen Ansetzung ebd. 9.

67 Exemplarisch Gen 49,10: "Nicht weicht das Zepter von Juda, noch der Führerstab von seinen Füßen ..." 
3

Literarkritik

Unser Psalm ist, so wie er überkommen ist, nicht in einem Zuge verfaßt und literarisch fixiert worden. Er schließt Teile in sich, die hernach hinzugekommen sind. Schwerlich auf einen Schlag. Eher schon, ja, so gut wie sicher, nach und nach. Welches sind die hinzugesetzten Stücke?

\section{1}

Die Oberschrift in $v .1$

Die Bemerkung "Wallfahrtslied" 68 steht nicht nur an der Spitze des Psalms, der hier verhandelt wird, sondern auch, sich ${ }^{69}$ stetig und stereotyp wiederholend, vor jedem Text der Sammlung des Wallfahrtspsalters, Ps 120-134. Sie scheint so vorangestellt worden zu sein, um - nach der Einfügung der Sammlung in den größeren, sich sukzessive zum Psalter hin erweiternden Verband - unmißverständlich zu markieren und festzuhalten, inwieweit sich diese erstreckt, was zu ihr gehört und was nicht ${ }^{70}$. Der Vermerk ist demgemäß, mit entsprechender Wahrscheinlichkeit, nachträglich und redaktionell. Ja, er ist dies im vorliegenden Fal1, in 125,1 , sogar mit Sicherheit. Denn ursprünglich könnte er - trotz des umschriebenen Sachverhalts - allenfalls sein, entspräche ihm uneingeschränkt die Substanz des Folgetexts. Sie aber mutet, insbesondere in den Versen 3-5, keineswegs so an, als sei sie dazu erschaffen, auf Wallfahrtsstationen zum Zion - üblicherweise immer wieder - Pilger zu befassen. Ist es nicht schwer vorstellbar, daß der die uberwindung einer Krise und die Abwehr einer Versuchung erstrebende Text, der auch Elemente der Auseinandersetzung und Abgrenzung nach innen enthält, von vorne-

68 BAUMGARTNER, Hebräisches und aramäisches Lexikon, ${ }^{3} 1974$, 580 ; KEET, A Study of the Psalms of Ascents $1 \mathrm{ff}$; SEYBOLD, Die Wallfahrtspsalmen $13 \mathrm{ff}$.

69 Abgesehen von einer Variation in 121,1.

70 Zur Ergänzung der Argumente BEYERLIN, Wider die Hybris des Geistes $38 \mathrm{f}$. 
herein als Wallfahrtslied intendiert und in Gebrauch gegeben worden sein sollte? Spricht nicht mehr dafür, er sei erst im nachhinein umgewidmet und in den Verwendungszusammenhang "Wal1fahrten zum Zion" eingebracht worden? Man kann doch wohl kaum umhin, diese Fragen zu bejahen. Dann aber erscheint es als sicher, daß "Wallfahrtslied" erst nachträglich sekundär davorgesetzt worden ist.

3.2

Das letzte Wort in v. 1

Es ist hier - tunlichst kurz - an die literarkritische Implikation zu erinnern, die sich bei unserer textkritischen Abwägung zwangsläufig eingestellt hat: jšb, das Wort an der Nahtstelle zwischen $v$. 1 und $v$. 2, ist nur als Glosse erklärlich ${ }^{71}$. Es hat sich da einer hinreißen lassen zum Einschub eines kleinen Wortes vor den Sätzchen $2 a$ und b, die parataktisch einen Vergleich anstellen ${ }^{72}$ zwischen Jerusalem und dem Volke Jahwes. Dies um perfektionistisch klarzustellen, nicht Jerusalem selbst, die Stadt als solche, nein, genauergenommen jošeb jêû̌salăim, die Bewohnerschaft dieser Stadt, korrespondiere dem Gottesvolk. Es liegt auf der Hand und ist nachzuempfinden, daß hier unnötigerweise, kleinlich prosaisch und die Natur des Vergleichs verkennend expliziert worden ist - charakteristisch glossenhaft. Die Annahme ist unausweichlich: jšb ist interpoliert ${ }^{73}$.

3.3

Das dritte Glied in v. 2

Es besteht aus der Formel, die in der Dichtung des Alten Testa-

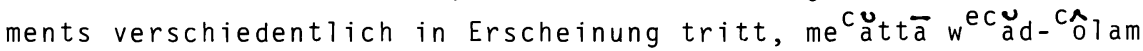

71 Aufweis in Ziffer 2.2.

72 MEYER, Hebräische Grammatik III, 1972, 100/101.

73 Beachtenswert nebenbei, daß auch VAN DER PLOEG, II 366, mit der Möglichkeit dieser Einfügung rechnet. Freilich, soweit zu sehen, mehr aus formalen Gründen. 
"von nun an und immerdar"74. Bei dieser Formel wird, wo immer sie alttestamentlich angewandt ist, die Ausgangsbedeutung des Bestandteils "von nun an" 75 nicht mehr so recht empfunden 76 . Das dritte Glied in v. 2 bringt also im Grunde genommen nicht mehr als noch einmal den Gedanken "auf Dauer" 77 , der, nur einen Augenblick vorher, am Schluß von v. 1, ein erstes Mal verlautet ist. Die so schnelle Wiederholung unter Wiederverwendung des Schluisselwortes $\mathrm{C} \hat{0} l a m$, die in der Sache nicht zwingend ist, weckt erste Zweifel daran, ob das Glied $2 c$ schon ursprünglich hinzugehört hat, ob es nicht vielmehr eingepflanzt ist. - Diese Zweifel verstärken sich noch, bedenkt man zugleich, daß sich das rhetorisch zergliedert breite stück an einen ausgewachsenen Parallelismus membrorum anschließt, an den Vergleichssatz $2 a$ und $2 \mathrm{~b}$, der wohlabgerundet und in seiner Zweigliedrigkeit auch lang genug ist, um eine Zeile auszufüllen ${ }^{78}$. Ist es nicht schwer vorstellbar, daß nach dem gewiß nicht kurzen parallelisierenden Satz "Jerusalem - Berge umhegen es; und Jahwe umhegt so sein Volk" es ursprünglich weitergegangen sein sollte "von nun an und immerdar"? Ist die so ausladende Dreigliedrigkeit nicht in jedem Falle zuviel des Guten, selbst wenn man annehmen wollte, da sei schon mit einer gewissen Lockerung des poetischen Formzwangs und einem Zug zum Prosaischen zu rechnen? - Alles in allem erscheint es geraten, $v .2 c$ als Zuwachs anzusehen und literarkritisch abzusetzen 79 .

74 Jes 9,$6 ; 59,21 ;$ Mi 4,7; Ps 113,$2 ; 115,18 ; 121,8 ; 131,3$.

75 Das Moment des Neueinsatzes gegenüber dem status quo ante.

76 Mit LOEWENSTAMM, The Formula me ${ }^{c}$ attā $w^{\text {ec }}$ ad ${ }^{c}$ olàm, in: Comparative Studies 166-170.

77 JENNI, Das Wort Cōläm, in: ZAW 64, 1952, $197 \mathrm{ff}$ und 65, $1953,1 \mathrm{ff}$ !

78 Selbstredend geht es nicht an, allein unter dem Eindruck der umknickenden Zeile in der BHS-Edition zu argumentieren. Anderwärts, im Kodex von Aleppo, dem musterhaften, sind die Zeilen ja anders arrangiert! Hingegen dürfte es sachgerecht sein, ausgehend vom Parallelismus membrorum, der zweifelsfrei existiert, zu folgern.

79 Im Endeffekt, nicht in der Herleitung, mit GUNKEL 550; 
3.4

Das Schlußstück in v. 5

Es besteht aus der Wendung Šalôm cŭl-jiśra ${ }^{2}$ el "Heil über Israel!" - Man setzt am besten mit der Feststellung ein, dieser Passus hänge mit dem voraufgehenden Text nicht sonderlich eng zusammen. Am wenigsten mit dem vorstehenden Teil von v. 5, der die Nicht-Gerechten "verwünscht" in schwergewichtiger, schwerfälliger Breite. Es ist schlechterdings unvorstellbar, daß das Schlußstück $5 c$ mit $5 a$ und $5 b$ zusammen einen Tristichos gebildet haben sollte 80 . Tat es dies nicht, dann bleibt - unter der Voraussetzung, daß poetisch gestaltet ist - nur die Annahme übrig, es stelle einen Kurzvers dar 81 , einen Monostichos. - Man könnte erwägen, ob dieser resümieren sollte, was im voraufgehenden Text verlautet, vor allem in $4 a-5 b$, in der Bitte für die Gerechten und im Wunsch wider die, die das nicht sind. Freilich bricht dann die Frage auf, ob die Wortwahl "Israel" in der Schlußpassage der scharfen Unterscheidung in den vorigen Sätzen entspricht, der Unterscheidung zwischen den "Guten", den redlich Gesonnenen, den "Gerechten" auf der einen Seite und denen, die solches nicht sind, auf der anderen Seite. Liegt es im Duktus dieser internen Scheidung und Unterscheidung, daß hernach pauschal "Israel" ins Auge gefaßt wird, "Heil über Israel"? Sollte die Frage vielleicht aus der überlegung heraus zu bejahen sein, da sei an das wahre Israel gedacht, unterschieden von dem gemeinhin so genannten? Indessen, wie sollte sich dies festmachen lassen? Immerhin, in Ps 1 , wo die Unterscheidung "nach innen" ganz ähnlich und in gleicher Schärfe gemacht ist, kommt "Israel"

H. SCHMIDT 225; OESTERLEY 512; KRAUS 1028; VAN DER PLOEG II $366 \mathrm{f}$ u.a.m. Natürlich kann man sich fragen, ob es notwendig war, das schon oft Angenommene neu zu begründen. Indessen, wer die Art der oft kargen Argumente betrachtet (vorausgesetzt, es werden überhaupt irgendwelche gebracht), wird die Notwendigkeit kaum bezweifeln.

80 Insoweit im Einklang mit MOWINCKEL, Real and apparent Tricola $89 \mathrm{f}$.

81 Vergleichenswert FOHRER, über den Kurzvers, in: ZAW 66, $1954,199 \mathrm{ff}$. 
nirgends zur Sprache, liegt der Gebrauch dieses Worts nicht annähernd in der Luft! Wer wollte behaupten, daß dieses zufällig sei? Ist es dann nicht unwahrscheinlich, daß der uns vorliegende Psalm am Ende so einfach "Israel" gesagt haben sollte? Nein, es spricht mehr dafür, es sei erst nachträglich dazu gekommen!

Auf einem Blatte für sich müßte der Gedanke zu stehen kommen, hier könnte mit liturgischer Wechselrede zu rechnen sein, mit einem Gegenüber zweier Stimmen. Hier, in $4 a-5 b$, sei in der einen Weise gedacht und gesprochen, dort, in $5 \mathrm{c}$, in einem anderen Duktus ${ }^{82}$. Derart auf ein liturgisches Gegenüber verteilt, erschiene die Divergenz zwischen der Masse des Texts, die "Gerechte" von Nicht-"Gerechten" abhebt, und dem Schlußwort, das "Israel" segnet, einigermaßen verträglich. Besonders allerdings dann, dürfte man dazuhin annehmen, der liturgische Psalm sei nicht einheitlich abgefaßt, sondern aus vorgegebenen Stücken zusammengefügt. Wäre er komplex, so fände, was divergiert, die überzeugendste Erklärung: in der Zurückführung auf verschiedene Autoren, vielleicht gar verschiedene Kreise. Bezieht man den Eindruck ein, der abschließende Passus, $5 \mathrm{c}$, mute eher als der voraufgehende Text, $1 a-5 b$, kultisch-liturgisch an ${ }^{83}$, so erlangt die Annahme das übergewicht, der Psalm sei, wenn überhaupt ein liturgischer, dann ein komplex liturgischer Text, zu einem solchen durch die Hinzufügung des Kurzverses $5 \mathrm{c}$ geworden.

Gleichgültig also, ob mit liturgischer Struktur gerechnet wird oder nicht, es empfiehlt sich in jedem Falle die Annahme, 5c habe seinen eigenen Ursprung gehabt und sei hinzugekommen 84 .

82 Mit dem Stichwort "liturgisch" und dem Gedanken an (priesterliche) Antwort wird ab und zu operiert. MOWINCKEL, Real and apparent Tricola 90. Im übrigen JACOB, Beiträge zu einer Einleitung, in: ZAW 16, 1896, 151ff; GRAETZ II 643; HERKENNE 126; LESLIE 126; TAYLOR 663 und nicht zuletzt KEET, Psalms of Ascents 48 .

83 Ein Eindruck, der sich uns noch vertiefen und bestätigen wird.

84 Zu dieser Annahme neigen einige, mit mehr oder weniger großer Bestimmtheit: so BAETHGEN 380; GUNKEL 549; OESTERLEY 512; KEET 48; VAN DER PLOEG II 366.368; KRAUS 1028; LORETZ 
3.5

Die Integrität ansonsten

Schaut man, was sich ergab, zusammen, so heben sich als literarkritisch sekundär vier kleinere Stücke ab: 1.) die Oberschrift "Wallfahrtslied" im Eingang von v. 1, 2.) die Glosse "Bewohnerschaft" an der Nahtstelle zwischen v. 1 und 2, 3.) die formelhafte Wendung "von nun an und immerdar" im letzten Glied von v. 2 und 4.) der Schluß-Monostichos "Heil über Israel!" v. 5c. Was hier aufgezählt ist, erscheint peripher, bedeutet Abstriche mehr oder weniger am Rande, läßt andererseits ein ansehnliches Textgut übrig, das fast ununterbrochen ist. Ist dieses der primäre Bestand, die ursprüngliche, noch nicht erweiterte "Einheit"?

Wer so fragt, gerät, ohne es zu wollen, in die Schußlinie einer gewissen "Textologie"85. Diese geht - ganz zu Recht, wer wollte's bestreiten? - davon aus, daß alttestamentiche Texte nicht statisch, sondern in sich dynamisch sind, daß sie neue Rezeptionen und Interpretationen auf sich ziehen können, sich aus einem Sitz im Leben heraus in einen anderen zu bewegen vermögen ${ }^{86}$. Es ist aber auch die nun freilich sehr fragwürdige Neigung im Spiel, die dem Text immanente Bewegung in eine Vielzahl von Schüben zu splitten. Mit dem Effekte, wenn nicht der Zerstückelung, so doch weitgehender Aufteilung. Sie mag im einzelnen Falle angehen können. Ob sie aber bei Psalmen, zumal bei kleinen, sachgerecht ist, muß füglich bezweifelt werden. Beim vorliegenden Psalm ist sie sicher nicht zuzugestehen. Woher sollte auch schon das Recht für die Behauptung zu nehmen sein, die eine Thematik könne mit einer anderen, mit einem bestimmten Motiv sich auf gar keinen Fall verbunden haben, ganz sicherlich nicht in ein und derselben literarischen Schicht? Wie sollte sich ausschließen lassen, daß

I I 259. Allerdings kommt auch hier die Begründung allermeist zu kurz. Was Anlaß und Rechtfertigung ist für unseren Versuch, eingehender zu argumentieren.

85 LORETZ II 475-477.7-9 und 257-260.

86 Insoweit ganz. selbstverständlich einig mit LORETZ II 477. 
im Kopfe eines Verfassers Themen und Motive verschiedener Provenienz zusammengedacht und verschmolzen worden sein können? Warum sollte, was der gedanklichen Arbeit des späteren Ergänzers, der das vermeintlich Unverträgliche ja dann doch zusammengebracht haben soll, ohne weiteres zugetraut wird, dem Verfasser der vorigen Schicht unter keinen Umständen zuzugestehen sein? Beide - nicht allein der Ergänzer, auch der voraufgehende Autor könnten ja ähnlich spät und in hinreichend fortgeschrittener Zeit am Werke gewesen sein. Spät und fortgeschritten genug, um Themen und Motive verschiedener Herkunft zu einen. Ergo sollte man nicht so leicht und schnell bei der Hand sein, das Vorhandensein einer Krasis von unterschiedlichen Themen und Motiven zum Anlaß für eine literarkritische Zertrennung zu nehmen. Spezieller gesprochen geht es nicht an, die Thematik um "Gerechte" und Nicht-"Gerechte" von der Motivik Jerusalem-Zion literarkritisch abzutrennen. Man bedenke hier nur, daß Ps 15 Gedanken, die ums "Gerecht"-sein kreisen, im Zusammenhang mit dem Zion denkt ${ }^{87}$ ! Warum sollte, was im genannten Gedicht so eng verwoben ist, in 125 auseinanderzunehmen sein? - Zudem ist strikt $z u$ bestreiten, daß es Sinn und Berechtigung haben könnte, zwischen dem Motiv des Jahwe Vertrauens und dem jenes Umhegt- und Geschuitzt-seins literarkritisch durchzuschneiden. Man betrachte da nur den Spruch Ps 32,10b "wer Jahwe vertraut, den umhegt er mit Huld"! So konzis dieser Satz auch ist, so vereinigt er doch in gekonntem, nicht anfechtbarem Gefüge bth bjhwh und sbb. Wer dürfte, was hier ursprünglich und eng zusammensteht, in 125, 1 und 2 zertrennen? Kurzum - wir brechen hier ab -, es ist schön und gut und im Prinzip auch richtig, daß Texte in der ihnen eigenen Dynamik "Schichten" anzusetzen vermögen, etwas pauschal gesagt. Es ist aber nicht schön, nicht gut und nicht richtig, gewiß nicht im vorliegenden Fall, daß ein so großer Anteil am kleinen psalmischen Text in vielen Impulsen und Schüben - fast "konglomeratisch" - zusammengekommen sein sollte. Da sind, wie an den Beispielen Ps 15 und 32,10 b ersichtlich, gedankliche

87 Dazu die Untersuchung des Vfs. Weisheitlich-kultische Heilsordnung, insbesondere die dortige Ziffer 7.1 . 
Zusammenhänge, die zu zerstückeln willkürlich ist ${ }^{88}$.

Der Gedankengang weist insgesamt Unebenheiten nicht auf: Die Jahwe vertrauen, stehen so dauerhaft fest wie der Zion, v. 1a$1 b^{89}$. Das Volk der Jahwe Vertrauenden ist von diesem seinem Gott so umhegt ${ }^{90}$ wie Jerusalem von den Bergen der Umgebung; das Vertrauen der Vertrauenden ist begründet, v. la-2b. Ebendarum $1 a ̈ ß t$ sich auch zusagen, das Zepter des Frevels, das frevlerische Regiment, bleibe nicht bestehen, v. 3a. Es ende gerade noch rechtzeitig, damit nicht auch noch die "Gerechten" ihr Vertrauen auf Jahwe verlieren und sich mit dem Frevel gemein machen, $v$. 3b. Eine Bitte für die "Gerechten", v. 4a.4b, und ein Wunsch wider die, die un-"gerecht" sind, v. 5a.5b, flankieren die Zusage und wirken darauf hin, daß, was zugesagt ist, baldigst Wirklichkeit wird. Wo sind da störende Nähte, die vom Messer des Literarkritikers aufgetrennt werden wollen? Läuft nicht vielmehr das Gewebe der Gedanken nahtlos durch? So, daß literarische Integrität ohne Schwierigkeiten anzuerkennen ist ${ }^{91}$ ? V. 1a-1b (ohne das Wort jšb).2a-2b.3a-5b - das ist ursprünglich zusammenhängender Text! Ihn "Einheit" zu nennen kann weder verfehlt noch verboten sein. Auch ist nicht zu bestreiten, daß der Psalm, so wie er uns heute vorliegt, "erweiterte Einheit" ist, erweitert durch allerlei Zusätze: durch die überschrift vor lab, die Glosse am Ende von 1, den formelhaften Einschub $2 c$ und den monostichischen Schluß 5c. Bei fast allem Hinzugesetzten, am wenigsten bei besagter Glosse, wird sich Zug um Zug erweisen, daß sich jene Bewegung auswirkt, die, dem Text immanent, ebendiesen von einem Verständnis ins andere versetzt, vom ursprünglichen Sitz im Leben in einen anderen, neuen ${ }^{92}$.

\footnotetext{
88 Woran auch "kolometrisches" Zählen nichts ändert.

89 Abzüglich jšb.

90 Dieselbe Motiveverbindung wie im mašal Ps $32,10 \mathrm{~b}$ !

91 Allenfalls mit dem winzigen Vorbehalt, da könnte vielleicht im Bereich von Bitte und Wunsch, am Ende des "Halbverses" $5 \mathrm{a}$, ein zusätzliches "Jahwe" eingefügt worden sein; überflüsigerweise, nachdem es in 4 a schon steht. Gewißheit ist schwer zu erlangen. Da die Bezeugung einhellig ist, könnte sich's eher um eine literar-als um eine textkritische Frage handeln. So oder so um eine ganz marginale.
}

92 Insoweit im prinzipiellen Einklang mit LORETZ II $476 \mathrm{f}$. Was 
4

Stilkritik

Unter diesem Aspekt nur das Nötigste. Vorab zum ursprünglichen Text.

4. 1 .

Zum primären Bestand

Dieser ist, nach den Satzarten beurteilt, zweigeteilt. Der erste, v. 1a-2b umfassende Teil wird im Unterschied zum zweiten, mit v. 3 beginnenden Abschnitt im wesentlichen von Nominalsätzen gebildet. Diese umschreiben Zuständliches: Es ist so, war so und wird so sein ${ }^{93}$, daß, wer immer Jahwe vertraut ${ }^{94}$, so gegründet, nicht wankend, nicht schwankend steht wie die Anhöhe Zion. Es ist so, war so und wird so sein, daß Jahwe die Seinen schützend umgibt - so beständig, wie Berge Jerusalem umstehen. Stabile Zuständichkeiten, die sich wandelnde Situationen und Wechselfälle der Geschichte "durchstehen". Unerschütterliche Fundamente, die Halt finden lassen, Halt auf Dauer. Der eingebundene kleine Verbalsatz, 1b, verwischt den Charakter des zuverlässig Zuständlichen nicht. Er unterstreicht ja auch nur auf seine Weise die Dauer der Stabilität. - Im anderen, zweiten Teil ist totaliter aliter stilisiert: in einer Kette von Verbalsätzen mit imperfecta

von diesem trennt, sind Bedenken gegenüber Eigenheiten seiner

"textologischen" Praxis, besonders gegenüber der Art, wie bereits Verschiedenheit von Themen und Motiven zum Anlaß genommen wird, literarkritisch zu sezieren, II 258-260. Vorbehalte gegenüber der "kolometrischen" Komponente seiner "Textologie" wiegen, wenisgtens im gegebenen Fall, vergleichsweise weniger schwer.

93 MEYER, Hebräische Grammatik III 9.

94. Nicht sich selbst und eigenen Mitteln; nicht anderen, nicht Menschen und schon gar nicht denen, die frevelnd Macht innehaben. 
und imperativa, die künftiges Geschehen umschreiben, die dieses teils indikativisch zusagen, $3 a$, teils imperativisch erflehend oder jussivisch wünschend erwirken, $4 a-5 b^{95}$. Es ist so im ganzen zweiten Teil um künftiges Gotteshandeln zu tun, das die gegenwärtige Notlage endet. - Es ist klar, daß der zweite Abschnitt auf dem ersten basiert: Alles Aussein auf Gott und, was von inm her geschieht, gründet im Vertrauen auf ihn, der sein Volk so beständig umhegt.

Nicht nur die syntaktischen Formen, mit denen stilisiert worden ist, sind bezeichnend und aufschlußreich. Vielmehr auch die Stilfiguren ${ }^{96}$. - Hervorstechend die wiederholt gebrauchte Figur des Vergleichs! Sie ist einmal, in v. la, mit der Vergleichspartikel $\mathrm{k}^{\mathrm{e}}$ bewerkstelligt, das andere Mal, in v. 2a.2b, mit Waw adaequationis und parataktischem Komparativsatz ${ }^{97}$. Beidemal werden - zum Behufe der Veranschaulichung - Bilder vor Augen gestellt, die Glaubenserfahrungen verdeutlichen. Im festgegründeten, nie wankenden Gottesberg Zion wird die festgegründete, nie ins Wanken geratende Existenz der Gott Vertrauenden anschaulich. In den Bergen, die Jerusalem schützend umgeben, tritt in gewisser Weise die Schutzmacht Jahwes vor Augen, die verläßlich die Seinen umhegt. Beide Vergleiche sind in der Kontemplation gewonnen ${ }^{98}$, die, was die Existenz des Gottesvolks und der Jahwe vertrauenden Einzelnen auszeichnet, in Zion-Jerusalem transparent werden sieht. - Nur einen Augenblick später, in v. 3a, treten weitere Stilfiguren hervor: die ineinandergreifenden Figuren Concretum pro abstracto und symbo ${ }^{99}$. Dịe Sprache kommt nicht

95 Auch 3b bezieht sich auf Künftiges, freilich auf solches, das abgewandt werden soll.

96 Zum Folgenden KONIG, Stilistik; RIDDERBOS, Die Psalmen. Stilistische Verfahren; BOHLMANN / SCHERER, Stilfiguren der Bibel.

97 GESENIUS / KAUTZSCH, Hebräische Grammatik, 261896, 494; MEYER, Hebräische Grammatik III, 31972, 91.100.10i.

98 TAYLOR 660; MANNATI / DE SOLMS 146.

$99 \mathrm{Vgl}$. neben BOHLMANN / SCHERER, Stilfiguren der Bibel $71 \mathrm{ff}$ ALONSO-SCHOKEL, Das Alte Testament als literarisches Kunstwerk $307 \mathrm{ff}$ ! 
etwa abstrakt auf das Regiment des Frevels, das die Lage so notvoll macht. Sie ist vielmehr - wie bisher so auch jetzt - bestrebt, sinnfällig-anschaulich zu bleiben. Sie stellt, konkret statt abstrakt, das Zepter des Frevels vor Augen, den Stab, der die Herrschaft, die Herrschaftsausübung symbolisiert. Da zeichnet sich - scheinbar jählings - das frevlerische Zepter ab, das drückend, verführend, gefährlich "über dem Los der Gerechten" ist. V. 3a vergewissert, daß, was hier irritierend vor Augen ist, verblassen und verschwinden wird. - Bedenkt man es recht, so ist die Abfolge der bisherigen Bilder in der absichtsvoll anschaulichen Rede so jäh und überraschend nicht: Erst die Anhöhe Zion; das von Bergen umgebene Jerusalem; dann jenes Zepter! Gehört ebendieses nicht nachgerade zu Jerusalem-Zion, von wo aus normalerweise das Zepter ausgereckt wird, wenn es mit rechten Dingen zugeht, das Zepter Jahwes ${ }^{100}$ ? Es wird unter dem Gesichtswinkel der Stilkritik deutlicher noch als bislang, wie sehr $v$. la-3a zusammengehören. - Verwandte Figuren kommen auch in der folgenden Wendung "über dem (Land-)Los der Gerechten" zum Zug: einerseits Concretum pro abstracto, andererseits Pars pro toto! Denn gewiß geht es nicht bloß darum, daß die Unrechtsherrschaft den Landbesitz der "Gerechten" tangiert. Vielmehr trifft sie ihr ganzes Leben, ihre Existenz in toto. Ihr Landlos, gôral, wird pars pro toto erwähnt. Abermals aus dem sichtilichen Bestreben heraus, konkret-anschaulich zu sprechen. - Diese Bestrebung bestimmt auch noch den Halbvers 3b. Dieser sagt ja nicht einfach, es möchte nicht dazu kommen, daß sich auch noch die "Gerechten" aufs Unrecht einstellen. Nein, er lenkt, um das abzuwendende Handeln und Sich-verhalten augenfällig hervortreten zu lassen, synekdochisch und pars pro toto ${ }^{101}$ den Blick auf die nach der Bosheit sich austreckenden Hände, meint aber, indem er die Teile fürs Ganze, die Organe für die Organismen vor Augen stellt, die "Gerechten" selbst, sie aber gerade unter dem Aspekt ihres "Handelns". - Dieser Hang zur Veranschaulichung und Verwendung ge-

100 Man vgl. nur etwa Ps 110,2 !

101 KONIG, Stilistik $50 \mathrm{ff} .59 \mathrm{ff}$; (KAYSER, Das sprachliche Kunstwerk, 171976, 112;) BOHLMANN / SCHERER, Stilfiguren $76 \mathrm{f}$. 
eigneter Stilfiguren hält sich bezeichnenderweise bis zum Schluß des primären Textes durch: Denn natürlich sind auch jene krummen, gewundenen Wege in $v$. $5 a$ bezeichnendes Bild. Die hier eingesetzte Stilfigur der Metapher steht, bekanntermaßen, für nicht geradliniges, "ungerechtes" Handeln und Sich-verhalten. - In summa kommt überzeugend zutage, daß es dem ursprünglichen Text zur Gänze eigentümlich ist, in eindringlichen Bildern zu veranschaulichen. Es ist Ausfluß dieser doch wohl auch pädagogischen Tendenz, daß die verzeichneten Stilfiguren samt und sonders "Tropen" sind, also ein und derselben klasse entstammen ${ }^{102}$. Wer könnte nachgerade an der Kohärenz des primären Textes noch zweifeln? Sie besteht, erwiesenermaßen, keineswegs bloß gedanklich, sondern auch stilistisch ${ }^{103}$. Da ist durchgestaltet, wenigstens in einer Perspektive der Stilkritik ${ }^{104}$ !

Arrondierend ist festzustellen, daß - punktuell und vereinzelt, nicht durchgängig charakterisierend - auch andersgeartete Stilfiguren mit in Erscheinung treten. Zum einen: deutliche "Leittöne"105, laut werdend im zweimal gesagten hăș̆ğddîqîm, v. 3a.3b, zudem wohl auch im wiederholten sabîb, v. $2 a . \ddot{2} \dot{b}$. Es wird so unüberhörbar, daß es dem ursprünglichen Text nicht um jeden in Israel geht, auch nicht um dieses an sich, sondern besonders und sondernd um die "Gerechten", die auch als "die Guten", die "geradlinig Gesonnenen", v. 4a.4b, zur Sprache kommen. Ihnen gilt im Grunde genommen, was mit dem doppelten sabib vergewissernd ausgesagt wird: daß Jahwe um die Seinen her ist. Zum anderen könnte als Stilfigur, als eine, wenn nicht der Verhüllung, so doch der Vermeidung unumwundenen Benennens ${ }^{106}$, in Erwägung zu ziehen sein, daß in der Zusage v. 3a ("... nicht wird bleiben

102 BÜHLMANN / SCHERER, Stilfiguren 63-81!

103 Was in der oben vertretenen literarkritischen sicht der Dinge natürlich erheblich bestärkt!

104 Zu SEYBOLD, Die Wallfahrtspsalmen $49 \mathrm{f}$.

105 KONIG, Stilistik 302/303; BÜHLMANN / SCHERER, Stilfiguren 23; VAN DER PLOEG II 365.

106 BÜHLMANN / SCHERER, Stilfiguren $83 \mathrm{ff}$. 
das Zepter des Frevels ...") das eigentlich handelnde Subjekt, der die Geschichte wirkende Jahwe, unausgesprochen im Hintergrund bleibt - was in zukunftsorientierten Worten des Alten Testaments so selten nicht ist ${ }^{107}$.

Bemerkenswert nicht zuletzt, daß einem anderen Stilmittel, das für das alttestamentliche Schrifttum und für die Psalmen insonderheit von erheblicher Wichtigkeit ist, geringere Bedeutung als den Stilfiguren zukommt: nämlich dem Parallelismus membrorum ${ }^{108}$. Begreift man dieses Stilmittel nicht so weit, wie neuerdings propagiert ${ }^{109}$, sondern beharrt einstweilen darauf, daß, solange von Parallelismus membrorum gesprochen wird, auch Sinnparallelität der Glieder erkennbar sein muß ${ }^{110}$, so findet er sich lediglich zweimal: in v. 2a.2b zum einen, in v. 4a.4b zum andern. - Bei v. la.lb tritt synthetisierende Zweigliedrigkeit zutage. Als Parallelismus membrorum im engeren und eigentlichen Sinn ist diese aber nicht zu werten. Bei v. 5a.5b fällt diese Einstufung ebenso schwer. Zweigliedrigkeit ist, wenn überhaupt, dann nur ganz schwach ausgeprägt. Und die Parallelität reicht nicht weit, nicht weit genug. - Die beiden Sätze, die zwischen v. 2 und v. 4, wo gesichertermaßen Parallelismus membrorum besteht, sich in einiger Breite erstrecken, weisen - je in sich Zäsuren nicht aufll. Sie laufen durch und füllen je eine Zeile.

107 Man vgl. z.B. noch einmal Gen 49,10! - Kaum nötig klarzustellen: Antonomasie liegt so wenig vor wie Passivum divinum. Wohl aber eine Art der Stilisierung, die tendenziell nahekommt.

108 ALONSO-SCHOKEL, Das Alte Testament als literarisches Kunstwerk $191 \mathrm{ff}$.

109 In dem von KUGEL vorgelegten höchst beachtlichen Buch The Idea of Biblical Poetry. Parallelism and Its History 1-58.

110 Sei es thetisch-synonyme oder thetisch-komplementäre, sei es andererseits antithetische. Bei synthetischer Gedankenführung kann von Parallelismus membrorum schwerlich die Rede sein. Im Anschluß an SEGERT mündlich. Vergleichenswert dessen Aufsatz Parallelism in Ugaritic Poetry, in: JAOS $103,1983,295 \mathrm{ff}$.

111 Auch nicht die "leichte Pause", die für die von KUGEL schematisierte Struktur der "parallelistic line" ganz unerläßlich ist. Siehe Anm. 109! 
Da sie gedanklich sehr eng zusammengehören und für eine "volle Pause" nicht Raum lassen, ist 112 hier, bei $v$. 3a.3b, zu bemerken, der Sinn springe von einer Zeile in die nächste hinüber, hier erfolge ein "Zeilensprung"113. - Aufs Ganze gesehen gliedert sich so der ursprüngliche Text des Psalms in 6 einigermaßen gleich lange Zeilen. Unterstellt man hierbei - erklärtermaßen hypothetisch -, das Wort "Jahwe" sei in der letzten Zeile, in 5a.b, irgendwann hinzugefügt worden, sei es im Laufe der Textweitergabe, sei es zuvor ${ }^{14}$, so ergäben sich gar frappierend gleich lange Zeilen. Läßt man sich, um dies darzustellen, für einen Augenblick auf das fragwürdige Verfahren ein, Quantitäten durch Konsonantenzahlen zu umschreiben ${ }^{115}$, so zeichnet sich ab: Zahl der Konsonanten

$\begin{array}{llll}\text { in Zeile } 1 \text { (v. 1a.1b): } & 29 & (18+11) \\ \text { in Zeile } 2(v .2 a .2 b): & 29 & (16+13) \\ \text { in Zeile } 3(v .3 a): & 28 & \\ \text { in Zeile } 4 \text { (v. 3b) : } & 29 & \\ \text { in Zeile } 5(v .4 a .4 b): & 29 & (16+13) \\ \text { in Zeile } 6 \text { (v. 5a.5b): } & 30 & \end{array}$

112 In Anlehnung an KAYSER, Das sprachliche Kunstwerk 90.

113 Enjambement. LORETZ, II 260, spricht von dieser Erscheinung bereits bei v. $5 a .5 b$ sowie be $i v$. $3 a$, einem dem Sinn und dem Redefluß nach ohne Frage durchlaufenden Satz. Seltsam, daß er diesen in zwei Kola, zwei Stichen, zergliedert. Wohl nicht zuletzt aus "kolometrischen" Gründen. $15+13$ Konsonanten sind angenehm; 28 aneinander nicht. In diesem Zusammenhang ist zu fragen, wie es mit dem vieifach belegten "Fünfer mit durchgehendem Satz" gehalten werden soll. BEGRICH, Der Satzstil im Fünfer, $135 \mathrm{ff}$ ! Warum sollte ihm nicht relativ zu einem einzeinen Kolon - doppelte Quantität zukommen? Ergo nehmen wir am Umfang der Zeilen $3 a$ und $3 b$ keinen Anstoß. Wir bräuchten auch dann keinen zu nehmen, sollte es sich bei $3 a$ nicht um einen Fünfer, sondern um einen Sechser mit durchgehendem Satze handein.

114 Siehe Anm. 91!

115 Ohne etwa Rücksicht zu nehmen auf die Frage, wieviele matres lectionis mitgezählt werden. 
Mithin ist eklatant, daß der ursprüngliche Text, wiewohl das Stilmittel des Parallelismus mebrorum als Regulativ nur mäßig mitgewirkt hat, in bestechendem Gleichmaß gegliedert ist.

Auch regelmäßige rhythmische Gliederung scheint ihm nicht abzugehen ${ }^{116}$. Unter Berücksichtigung der Beziehungen, die zwischen Rhythmus und Sinn bestehen, könnte die rhythmische Gliederung so zu symbolisieren sein:

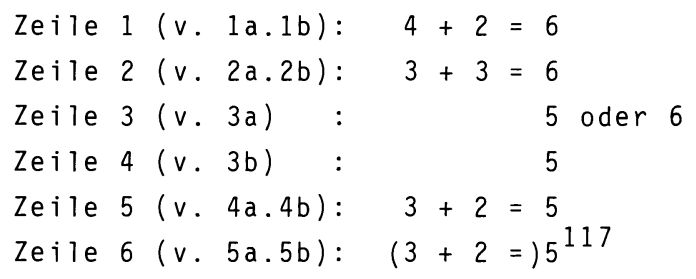

Das Schema scheint widerzuspiegeln, was sich, als wir syntaktische Formen erhoben, ergab: Dort, wo im wesentlichen Nominalsätze ausdrücken, welches die Grundlagen sind, auf die rekurriert werden kann, ergeht sich die Rede in Sechsern, in relativ breiten Senaren. Dort, wo Verbalsätze sagen, was zur Abwendung der Not geschehen - oder auch nicht geschehen - soll, dominiert offensichtich der Fünfer. Es scheint geraten zu sein, hierbei offen zu lassen, ob, was $v$. 3a zusagt, als so sicher aufgefaßt ist, daß es besagten Grundlagen gleichgeordnet und entsprechend als Sechser gesprochen wird. Die Schwierigkeit, zu entscheiden, wie die Zeile des Umschwungs, v. 3a, rhythmisch gegliedert ist, könnte insofern nicht zufällig sein. Wie dem auch sei-auch in dieser Dimension des Textes stellt sich, mindestens aufs große Ganze gesehen, erstaunliche Regelmäßigkeit heraus.

Alles in allem erscheint es vertretbar, den in mehr als einer Beziehung recht gleichmäßig stilisierten primären Bestand als "poetisch" einzustufen. Wird doch völlig zu Recht betont, daß

$116 \mathrm{Zu}$ den Voraussetzungen, die hier im Spiel sind, ALONSOSCHOKEL, Das Alte Testament als literarisches Kunstwerk $77 \mathrm{ff} .132 \mathrm{ff}$.

117 Wird "Jahwe" als primär verrechnet, ergibt sich $(4+2=) 6$. 
Poesie in formaler Hinsicht auf nichts so sehr beruht wie auf Regelmäßigkeiten der Gestaltung, mit welchen ein wohlbegrenztes $M a ß$ an Variationen einhergehen kann ${ }^{118}$. Andererseits wird nicht minder zutreffend festgestellt, daß es gänzlich abwegig ist, mit Poesie nur rechnen zu wollen, wo Parallelismus membrorum angewandt ist, durchgängig gar und textumfassend. Er kommt zwar im alttestamentichen Schrifttum, das als poetisch angesehen wird, verhältnismäßig häufig vor. Häufig, aber nicht obligatorischdurchweg! Andererseits ist er im prosaischen Schrifttum gleich möglich. Wo immer er zur Anwendung kommt, bewirkt er Nachdrücklichkeit und vor allem gehobene Sprache. So muß es uns darum gehen, zusammenzuschauen und zu würdigen, was an "heightening effects", an Faktoren, die gehobene Sprache erzeugen, im gegebenen Text zusammenwirkt ${ }^{119}$. Und da kommt nicht wenig zusammen:

Da is Ebenmaß der Gestaltung in mehreren Dimensionen des Texts. Ebenmaß mit Variation. Einerseits im Wechsel des Rhythmus von Sechsern zu Fünfern. Andererseits in der begrenzten Lockerung der Straffheit der durchgehend gleich langen Zeilen ${ }^{120}$. Da ist überdies mit vielen Tropen gestaltet. Und zweimal steigert, zu allem hin, das Stilmittel des Parallelismus membrorum den Pegel der gehobenen Sprache. Er ist so hoch, daß sicher kein Grund besteht, dem Primärtext des Psalms poetischen Charakter abzusprechen. Wobei hinzuzubemerken ist, diese gewohnheitsmäßige, herkömmliche Einstufung trage zum Ergebnis kaum bei. Sie bestärke vielmehr in der fragwürdigen, wenig adäquaten Vorstellung, es gebe einen einfachen Gegensatz von Prosa und Poesie. Indessen, den gibt es nicht. Was es gibt, ist - mehr oder weniger gehobene Sprache, je in dem Maß, in welchem hebende Effekte zusammenwirken respektive ganz oder teilweise fehlen. - Was dem im vorliegenden Fall gegebenen gehobenen Sprachcharakter mit der Wirkung der Minderung anhängt, sind ein paar schwerfällige Wendungen, die seit langem und immer wieder vermerkt worden sind $^{121}$

118 KUGEL, The Idea of Biblical Poetry 69.

119 Mit KUGEL, The Idea of Biblical Poetry 59-95.

120 KAYSER, Das sprachliche Kunstwerk 90.

121 Beispielsweise von DELITZSCH 747, BAETHGEN 380 und GUNKEL 549. 
und kaum erneuter Erwähnung bedürfen. Sie machen die Individualität unseres Psalmes mit aus.

\section{2}

Zum sekundären Bestand

Es ist klar und ganz unbestritten, daß auch die sekundären Stücke des Psalms stilkritischer Würdigung wert sind. Im gegebenen Fall genügen jedoch einige wenige Feststellungen. Zunächst einmal die, daß nicht alle Zusätze gehobene Sprache aufweisen. Gewiß nicht die überschrift "Wallfahrtslied". Und natürlich auch nicht die Glosse zwischen $v$. 1 und 2 . Sie gereicht ihrer Natur gemäß dazu, die Regelmäßigkeiten im Eingang des primären Bestands zu beeinträchtigen. - Andererseits ist der eingeschobenen Forme 1, v. 2c, das Gepräge gehobener Sprache keinesfalls abzusprechen. Nicht nur weil, wie schon früher erwähnt ${ }^{122}$, die Formel, jedenfalls in ihrem alttestamentilichen Vorkommen, ausschließlich "poetische", gehoben stilisierte Kontexte hat. Vielmehr auch, weil sie in sich selber entsprechend gestaltet ist. Sie ist, in ihrer hebräischen Fassung, unüberhörbar klanglich gereimt (durch Alliteration der Anfangsbuchstaben) ${ }^{123}$. Zudem waltet in ihr die Stilfigur des Merismus ${ }^{124}$. Endlich ist auch der Erweiterung $v$. $5 c$ eine gewisse Gehobenheit eigen. Bei der Kürze des Stücks ist sie nicht so ganz leicht zu erweisen. Vielleicht noch am ehesten dadurch, daß auch der andere Beleg dieser Forme1, Ps $128,6 \mathrm{~b}$, zu einem Kontext gehört, der gehobene Rede ist. - Im Blick aufs Ganze ist klar, daß alle Erweiterungsstücke, keineswegs bloß die in $v$. 1, den in mehr als einer Beziehung ebenmäßig gegliederten Psalm zerdehnen. Nach dem Parallelismus membrorum 2a.2b bleibt sichtlich kein Raum für einen Ausbau zur Dreigliedrigkeit. Ebensowenig nach dem nur ganz schwach gegliederten, aber jedenfalls füllig breiten

122 In Ziffer 3.3 und den Anmerkungen 74.76 .

123 ALONSO-SCHOKKL, Das Alte Testament als literarisches Kunstwerk 29.

124 BEYERLIN, Wider die Hybris des Geistes 52. 
Satz $5 a \cdot 5 b^{125}$. - Mithin scheint sich auch stilkritisch gesehen die Richtigkeit unserer literarkritischen Einschätzungen zu erweisen, die voraufgehend - nota bene aus anderen Gründen vorgenommen worden sind.

125 Vergleichenswert MOWINCKEL, Real and apparent Tricola 89. 


\section{5}

Obersetzung

Nachgerade ist nicht bloß am Tag, was primärer und sekundärer Bestand ist, sondern auch, wie sich ersterer gliedert. Der übersetzung des Texts steht nichts mehr im Weg. - Was sekundär ist, erscheint en petit und, soweit möglich, zum linken Rand hin versetzt.

1 ) Wallfahrtslied.

1a) Die Jahwe vertrauen, sind wie der Zionsberg:

1b) Er wankt nie.

Bewohnerschaft von

2a) Jerusalem - Berge umhegen es.

2b) Jahwe umhegt so sein Volk.

2c) Von nun an, fortan.

3a) Fürwahr, nicht wird (lasten) bleiben das Zepter des Frevels auf dem Los der Gerechten,

3b) daßnicht (auch noch) die Gerechten zum Unrecht die Hände recken.

4a) Tue Gutes, Jahwe, den Guten,

4b) den geradlinig Gesonnenen!

5a) Doch die krummen Weges abbiegen, die lasse er (Jahwe) fahren

5b) mitsamt den Ubeltätern!

5c) Heil über Israel! 

6

Traditionskritik

Mit ihrer Hilfe ist noch tiefer in die gedankliche Substanz unseres Psalms, seines primären und sekundären Bestands, einzudringen; von der Frage geleitet, welche Traditionen -, welche geprägten geistigen, vorstellungsmäßigen Welten ("Rückräume"), den Verfasser des primären Gedichts und dessen Bearbeiter angeregt und bewegt, bestimmt und beeinflußt haben ${ }^{126}$. Die Frage ist in einem ersten Durchgang beim ursprünglichen Bestand zu verfolgen; in zweiter Linie dann auch bei den wichtigsten Zusätzen.

6.1

Beim primären Bestand

Es sind mehrere Traditionen, die eingewirkt haben und die voneinander zu unterscheiden sind. Wir spüren zunächst der Einwirkung nach, die, wie es scheint, am breitesten greift.

6.1 .1

Weisheitstradition

Auf ihre Fährte bringt - für sich alleine genommen gewiß nicht zwingend, wohl aber Verdacht erweckend - der Umstand, daß in dem wahrlich kurzen ursprünglichen Text fünf, wenn nicht sechs, Vokabeln vorkommen, die auffallend häufig und sichtlich gern, allerdings mitnichten ausschließlich, im weisheitlichen Schrifttum des Alten Testaments verwendet worden sind. Es ist klar, daß sie, trotz ihrer Massierung, Weisheitlichkeit nicht bewirken. Es ist aber nicht weniger klar, daß sie symptomatische Anzeichen sein können, hier äußere sich sapientiale substanz ${ }^{127}$. -

126 Siehe etwa BARTH / STECK, Exegese des Alten Testaments, $\S 8,77 \mathrm{ff}$ ! Vgl. dazuhin BEYERLIN, Wider die Hybris des Geistes 71, besonders auch die dortige Anm. I!

127 Man vgl. die Vokabel-Listen bei SCOTT, The Way of Wisdom 121 sowie bei KUNTZ, The Canonical Wisdom Psalms 201! Beachtenswert MURPHY, Assumptions and Problems in $01 d$ Testament Wisdom Research, in: CBQ 29, 1967, 410. 
Da ist, gar wiederholt und in Leittonfunktion ${ }^{128}$, das Wort săddîq zu vernehmen. Parallel dazu, höchst bemerkenswerterweise, jašar. Verknüpft mit dieser Vokabel noch leb, v. 3-4. So ist von "Gerechten" die Rede, welche im "Herzen" - besser: im "Geiste" - "geradlinig" sind"129. Was den Befund noch bezeichnender macht, ist der augenfällige Umstand, daß kontrastweise zusätzlich Căwlā und Jawaen gebraucht sind; dazuhin, wenn nicht rašac, so doch immerhin raešac130. Den Psalmisten bewegt, daß besagte Gerechte, Herzensgeradlinige, sich in anfechtender Weise dem "Unrecht", "übel" und "Frevel" gegenübersehen. Oder auch personalisiert: Unrechttuenden, Ubeltätern und Frevlern, v. 35b. - Der symptomatischen Wortwahl entspricht eine gedankliche Substanz, die per se typisch weisheitlich ist ${ }^{131}$ :

Da wird - so wie es für sapientiale Psalmen und für Weisheit allgemeiner kennzeichnend ist - die Handlungs-, die Verhaltensweise der Gerechten mit der der Nicht-Gerechten kontrastiert. Allerdings, unser Text ist zu kurz und zu sehr in der Zusage eines Wandels der Dinge zentriert, als daß er dies beschreibendausführlich zu tun vermöchte. Er kontrastiert vielmehr nebenbei, aber doch noch bezeichnend genug: Da sind einerseits die, die krumme Wege einschlagen, obel tun und sich übel verhalten, aber auch, wenn Gott will und dem Wunsch des Psalmisten entspricht, letzten Endes "dahinfahren", v. 5ab. Da sind andererseits die sŭddîâm, die Gerechten, die Guten, die Geradlinigen, die unter dem Zepter des Frevels leiden, die wohl auch der Versuchung unterliegen, sich aufs Unrecht einzustellen, die ihr aber noch nicht erlegen sind und, so Gott will und die Bitte erhört, letzten Endes Gutes erfahren, v. 3-4. - Der Kontrast tritt so scharf zutage, wie das weisheitsspezifisch ist.

Mit der nachgezeichneten Kontrastierung ist aufs engste eine überzeugung verbunden, die nicht weisheitsspezifisch, indessen

128 Siehe Ziffer 4.1!

$129 \mathrm{Vgl}$. in der Liste nach KUNTZ die Nummern 29.34.50!

$130 \mathrm{Vgl}$. in der nämlichen Liste die Nummern 1.45.56!

131 Zum Folgenden KUNTZ, The Canonical Wisdom Psalms $213 \mathrm{f}$. 
nirgends so sehr reflektiert worden ist wie gerade bei Israels Weisen: die Oberzeugung nämlich, daß von gutem oder bösem Tun je entsprechende Wirkungen auf die Täter selber ausgehen ("TunErgehen-Entsprechung", "schicksalwirkende Tatsphäre") ${ }^{132}$. Im gegebenen Psalm spricht sich diese Grundüberzeugung mit aller Deutlichkeit aus: Es entspräche der Ordnung der Dinge, widerführe "den Guten Gutes", denen jedoch, "die krummen Weges abbiegen", daß sie, ereilt von der Wirkung ihres eigenen Tuns, auf ebendiesem Weg "dahinfahren", will wohl sagen, zugrunde gehen, v. 4.5. Kommen diese Gedanken just im Zuge jener Kontrastierung zum Tragen, so erweist sich hier zuverlässig, daß der Psalmdichter in der überlieferung der Weisheit steht, daß er aus ihr heraus denkt und dichtet.

Es springt nicht aus den Bahnen dieser überlieferung heraus, wenn er zugleich zu erkennen gibt, daß die Verwirklichung der Entsprechung zwischen Tun und Ergehen verzögert und aufgehalten ist. Noch ist das Zepter des Frevels im Weg. Noch herrscht Unrecht und droht zu verführen, v. 3. Noch bedarf es der Bitte und des Wunsches, daß Jahwe die Ordnung der Dinge herstel1t, die Korrespondenz zwischen Tun und Ergehen, die der Ordnung entspricht, v. 4.5. Der Weisheit ist wohlbewußt, daß der Vol1zug dieser Korrespondenz Gott vorbehalten und dem Menschen nicht verfügbar ist, daß er Sache des Wartens und des Vertrauens auf Gott sein kann133. - Was Wunder, wenn der vorliegende Psalm, der so sichtlich aus der Spannung erwuchs, daß die Entsprechung zwischen Tun und Ergehen faktisch noch unverwirklicht ist, auf Vertrauen abhebt, auf vertrauensvolles sichverlassen auf Jahwe, v. 1! Täte er's nicht, so müßte man das Werben und Drängen, Vertrauen auf Gott zu bewahren, zwischen den Zeilen suchen. - Gleichzeitig ist klar, daß der Psalmdichter

$132 \mathrm{KOCH}$, Gibt es ein Vergeltungsdogma im Alten Testament? Ders. (Hg.), Um das Prinzip der Vergeltung; VON RAD, We isheit in Israel $165 \mathrm{ff}$.

133 GESE, Lehre und Wirklichkeit in der alten Weisheit $38 \mathrm{ff}$; VON RAD, Weisheit in Israel 173. 
nicht allgemein vom Vertrauen auf Jahwe spricht ${ }^{134}$, sondern, speziell und spezifisch, vom Vertrauen auf den, der, trotz widriger Erfahrungen in Vergangenheit und Gegenwart, Gewähr dafür ist, daß Tun-Ergehen-Entsprechungen und mit ihnen die von Gott gewollte Ordnung menschlichen Lebens letzten Endes Wirklichkeit werden. Dieses Vertrauen liegt erwiesenermaßen ${ }^{135}$ volikommen im Duktus der Weisheit. So wird noch mehr klar, wie sehr diese Tradition den ursprünglichen Bestand unseres Psalms bestimmt.

Sie prägt auch diverse Details. So, gleich im Eingang des Texts, den aktivisch partizipialen Gebrauch von bth: "Die (auf) Jahwe vertrauen ..." Dieser ist, wie Konkordanzarbeit zeigt, vor allem sapiential im Schwang ${ }^{136}$. Beachtenswert der gehäufte Gebrauch in den Sentenzen der Spruchweisheit: bôte ${ }^{a}$ ? "der auf Jahwe vertraut, wird erquickt", Spr 28,25; bôte ${ }^{a} h$ "der auf Jahwe vertraut, ist geschützt (ist sicher)", Spr 29,25 ; bôte ${ }^{a}$ ? "der auf Jahwe vertraut, wohl ihm!", Spr 16,20. Zugehörig sind auch die die Kehrseite umschreibenden Sprüche: bôte ${ }^{a} h$ "der auf seinen Reichtum vertraut, kommt zuFal1", Spr 11,28; boteah "der (allein) auf sein Herz (seinen Geist) vertraut, ist ein Tor", Spr 28,26. Zuzuordnen ist nicht zuletzt der Weisheitsspruch Ps 49,7, der, Ps 125,1 noch weitergehend entsprechend, pluralisch partizipial formuliert: hăbbot "hîm "die auf ihr Vermögen vertrauen", sind furchterregende Menschen. - Daß die Weisen vom Vertrauen mit so ausgeprägter Vorliebe und Beständigkeit in partizipialen Bildungen sprechen, beruht auf tieferen Gründen: Sie wollen prägnant und in äußerster Kürze Erfahrungen wahrnehmen und "wahrsprechen", die allgemein gültig sind; nicht bloß für bestimmte Menschen, sondern für jeden, der durch das Verhalten und Tun gekennzeichnet ist, die das verwendete Verb bezeichnet. Es ist just die Form der partizipialen Bildung, die all dies in einem zu leisten vermag, die "ein Verhalten oder Tun und eine damit charakterisierte

134 Was dieses anlangt, so vgl. man VONCK, L'expression de confiance dans le Psautier lff!

135 Man lese etwa VON RAD, Weisheit in Israel $245 \mathrm{ff}$ !

136 MANDELKERN, Veteris Testamenti Concordantiae, I, 185. 
Person in einem Ausdruck" umfassen kann und so geeignet ist, das Subjekt im Weisheitsspruch in der erforderlichen Kürze zu umschreiben ${ }^{137}$. - Der Befund, daß die Weisheit, die Spruchweisheit, in auffallender Frequenz und Konstanz mit Partizipien von bth formuliert, ist mithin nicht von ungefähr, sondern ihr gemäß und typisch für sie. Ergo fügt sich bereits die Gestaltung im Eingang des Psalms exakt ins gewonnene Bild: in das eines weisheitsbestimmten Texts.

Blickt man zurück auf die oben zitierten Sprüche, so wird zudem klar, daß nicht nur die besondere Gestalt, sondern auch der gedankliche Gehalt - der im gesamten Eröffnungsvers 138 - ausgesprochen weisheitsgeläufig ist: "Der auf Jahwe vertraut, wird erquickt", " - ist beschützt / ist sicher"; so sehr, daß er glücklich zu preisen ist, Spr 28,25;29,25; 16,20. Der nicht auf Jahwe vertraut, sondern (nur oder vor allem) auf sich, sein Herz, seinen Geist, seinen Reichtum, "-kommt zu Fall" und erweist sich als "Tor", Spr 11,28; 28,26. Drückt sich hier und in unserem Psalmvers nicht ein und dieselbe gedankliche Grundsubstanz aus? Wer sich vertrauensvoll auf Jahwe verläßt, kommt nie ins Wanken, geschweige denn ganz zu Fall, ist existentiell so gesichert, daß er glücklich zu preisen ist. Es liegt auf der Hand: die Gedanken im Eingang des Psalms werden ${ }^{139}$ auch und gerade von Weisen bewegt. Nicht ausschließlich, aber besonders von ihnen ${ }^{140}$. Was der Psalmdichter sagt, geht alsolil übers sapiential Geläufige nicht hinaus.

137 HERMISSON, Studien zur israelitischen Spruchweisheit, besonders 163 .

138 Abgesehen vom Motiv, mit welchem verglichen wird. Dieses will für sich genommen und erörtert werden.

139 Vom Motiv, mit dem verglichen wird, zunächst einmal abgesehen.

140 So ist im Blick auf Passagen wie Ps 21,8 oder 26,1 präzisierend hinzuzufügen. Wobei zu bedenken sein könnte, in welchem Verhältnis solcherlei Stellen zur Weisheitsüberlieferung stehen.

141 Abgesehen von dem in Anm. $138 f$ genannten Motiv. 
Entsprechendes gilt von der Formel, die 125,1 beschließt: $10^{2}$ -

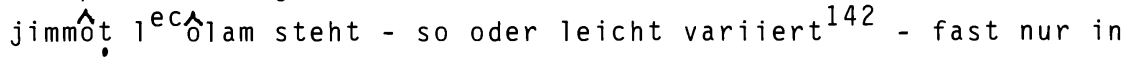
weisheitlichen Texten: Ps 15,5c gehört wie 112,6a zum sapientialen Textgut im Psalter ${ }^{143}$; Spr 10,30a, das versteht sich von selbst, zu Israels Spruchweisheit. Ps 30,7 und 10,6a sind gebrochene Reflexe derselben. In summa wird abermals klar, wie weisheitlich hier formuliert ist.

Dieser Eindruck bestätigt sich beim Verbund der Gedanken in 125,1 und 2. Denn die Folge Partizip von bth + bjhwh und sodann sbb "umhegen / schützend umgeben" findet sich, abgesehen vom vorliegenden Text, nur noch einmal: in Ps 32,10 , einem anerkannt weisheitlichen Spruch! Beide Texte sind zu verschieden ausgeprägt, als daß daran gedacht werden könnte, der eine hänge vom andern literarisch ab. Ergo bleibt nur eine Erklärung: die, der Verbund jener beiden Motive sei im Kreis der Weisen entstanden, sei hier vorgegeben gewesen und von dort her in diese beiden Texte hineingekommen.

Endlich sei noch vor Augen geführt, daß auch der Gedanke, der am Psalmschluß verlautet, die, die krumme Wege einschlügen, hätten auf diesen zugrunde zu gehen, nur in einer sparte des alttestamentlichen Schrifttums wiedervorkommt - ausgerechnet im Buch der Sprüche, in Sentenzen der Spruchweisheit; dort aber gleich wiederholt und unter konstanter Verwendung der oben erörterten signifikanten partizipialen Bildung, die nicht nur in 125,1a das Subjekt umschreibt, sondern auch in 125,5a. In Proverbien heißt es: "... wer krumme Wege einschlägt ${ }^{144}$, wird ertappt ${ }^{145}$,

142 Angaben im einzelnen bei CULLEY, Oral Formulaic Language $57 \mathrm{f}$.

143 Zum ersteren der beiden Psalmen: BEYERLIN, Weisheitlichkultische Heilsordnung. Studien zum 15. Psalm.

144 Partizip Pi. von Cq ${ }^{2}$. Dazu Baumgartner / Stamm, Hebräisches und aramäisches Lexikon, ${ }^{1983,828 f .}$

145 Oder, sollte der Emendationsvorschlag im Apparat von BHS das Richtige treffen, "... wird Unheil erfahren", Nif. von $r$ CC. 
Spr 10,9; "... wer krumme Wege ${ }^{146}$ geht ${ }^{147}$, fällt...", Spr 28,18. Hier läßt sich nur eines folgern: daß auch am Ende des Psalms nichts anderes als Weisheitsüberlieferung durchschlägt.

So steht als Ergebnis im ganzen, auf vielfache Weise untermauert, ganz unumstößlich fest: Der primäre Bestand unseres Psalms ist sowohl in der Substanz der Gedanken als auch in Details der Gestaltung ein ausgesprochen sapientialer Text. Der Einfluß der Weisheitstradition reicht in ihm so tief und weit, daß es gerechtfertigt und geboten erscheint, ihn den Weisheitsgedichten im Psalter zuzurechnen ${ }^{148}$.

Steht dies fest, so kann nicht mehr zweifelhaft sein, wie die Figur des Vergleichs einzuschätzen ist, die im Eingang des Psalms, in v. 1 und 2 , gleich zweimal angewandt ist. Sie wird ohne Rückgriff auf unseren Text - ohnehin schon seit einiger Zeit als charakteristisch weisheitliches Mittel erachtet ${ }^{149}$. Was aus mehreren Gründen einleuchtet: Erstens, weil die Form des Vergleichs in sapientialen Texten des Psalters relativ häufig erscheint, in Ps $1,3.4 ; 37,2.20 ; 49,13 ; 127,4 ; 131,2^{150}$ u.ö., in noch auffallenderer Massierung ausgerechnet im Buch der Sprüche, so in 10,$26 ; 11,22 ; 12,4.18 ; 15,19 ; 25,11-14.18-20.23-26.28$ und ebenso vielfältig in den Kapiteln $26.27^{151}$. Zweitens und tiefer gegriffen, weil der veranschaulichende Effekt des Vergleichs dem pädagogischen Eifer der Weisen dienlich ist und Einsichten vermitteln hilft. Drittens und last but not least, weil Vergleiche der Neigung der Weisen entsprechen, affine Strukturen in ver-

\footnotetext{
146 Wohl Plural statt Dual!

147 Partizip Nif. von Cqy!

148 Vergleichenswert KUNTZ, The Canonical Wisdom Psalms $186 \mathrm{ff}$.

149 KUnTZ, The Canonical Wisdom Psalms $198 \mathrm{f}$.

150 Zur Weisheitlichkeit dieses Psalmes: BEYERLIN, Wider die Hybris des Geistes, besonders $71 \mathrm{ff}$.

151 Ergänzende Angaben etwa bei GEMSER, Sprüche Salomos 95.97. Lesenswert auch noch immer DELITZSCH, Das salomonische Spruchbuch 9.10 .
} 
schiedenen Bereichen der Wirklichkeit zusammenschauend zu erfassen. - Sieht unser Psalmist in $v$. la die, die auf Jahwe vertrauen, und den Zionsberg zusammen, so deshalb, weil er Affines erkennt: Beide, sowohl die, die auf Jahwe vertrauen, als auch jener Berg, sind von Gott gegründet und ebenhierdurch unerschütterlich fest, v. $1 b^{152}$. Schaut er in v. $2 a .2 b^{153}$ das von Bergen umgebene Jerusalem und Jahwes Volk zusammen, so, weil er auch hier Affines entdeckt: Die Schutzmacht Jahwes umhegt sein Volk und seine Stadt; sie stellt sich in den machtvollen Bergen 154 rings um Jerusalem dar; sie ist hier in gewisser Weise sinnfällig wahrzunehmen. Liegt es, wenn dem so ist, für sapientiales Begreifen nicht nahe, das, was sich so entspricht, vergleichend in eins zu sehen und beim Werben um Vertrauen auf Jahwe und seine schützende Macht von dem auszugehen, was sinnfällig vor Augen ist? - Kurz: es ist offenbar, daß auch die Figur des Vergleichs weisheitlich bedingt und verursacht ist. So bestätigt sich, auch und gar traditionskritisch gesehen, daß die Vergleiche in $v .1$ und 2 zum ursprünglichen Bestand gehören. Sie sind als sapientiale Momente integrale Bestandteile des ausgemacht sapientialen Gedichts.

Letztlich ein Punkt, der auch traditions g e s c h i c h t $1 \mathrm{i} c \mathrm{~h}$ Anhalt zu bieten verspricht: Es ist die bereits verhandelte Verve, mit der es nicht etwa um Israel geht, sondern gezielt und mit sonderndem Vorrang um die "Gerechten", die săddîqîm, und die Abwendung der, wie es scheint, akut gewordenen Gefahr, sie könnten der Versuchung erliegen, aufs Unrecht einzuschwenken ${ }^{155}$. Die hier spürbar werdende Bemühung, die Gerechten von Verwicklungen mit dem Unrecht und den Ungerechten frei zu halten und von denen zu scheiden, "die krummen Weges abbiegen", bahnt sich fraglos bereits in der spruchweisheit an, wie etwa

152 Beachtenswert Ps $87,1 \mathrm{~b}$ und $5 \mathrm{~b}$ sowie, in nahe verwandter Beziehung, Ps 48,9 und 46,6 .

153 Siehe Anm. 72!

154 Vgl. VAN DER LEEUW, Phänomenologie der Religion 4lf!

155 Ziffer 3.4! 
an Spr 13,20 und 24,1 zu ersehen. Es ist aber unverkennbar, daß das Ringen um Scheidung und Meidung im Innern des Jahwevolkes bei den Weisheitslehrern der späteren Zeit intensiver und breiter hervortritt, Spr 1,10-19;4,14-19156. Ahnliches ist aus Ps 1,1 zu schließen, dem Eingang zu einem Text, der zum Spätesten im Psalter gehört: Er macht, triadisch breit und nachdrücklich, die Trennung von den unweisen Frevlern zur Grunderfordernis. Die Texte, die hier ins Feld geführt werden ${ }^{157}$, demonstrieren nicht nur - in kaum noch nötiger Weise -, daß auch dieses besondere, unseren Psalmtext kennzeichnende Moment sapiential zu deduzieren ist. Sie zeigen zudem, wie wahrscheinlich es ist, daß der um Scheidung und Meidung im Inneren besorgte Ps 125 spät entstanden ist.

\section{1 .2}

Prophetische Tradition 158

Zukunftsansage, sei sie drohender oder verheißender Art, gilt als "Hauptaufgabe der Propheten"159. Unser Psalm sagt in v. 3a ohne Frage Zukunft an: "... nicht wird (lasten) bleiben das Zepter des Frevels ..." Ist nicht folglich anzunehmen, da sei ein Schuß prophetischer Tradition im weisheitlichen Text eingewoben? Die Bejahung der Frage scheint nahezuliegen. Um so mehr, als Stileigenheiten ${ }^{160}$ weissagender prophetischer Rede augenscheinlich zutage treten ${ }^{161}$. Da fällt, so wie es Prophetenart ist, bei der Apostrophierung der Herrschaft des Frevels kein

156 PLOGER, Sprüche Salomos $3 \mathrm{ff.} 15 \mathrm{ff.} 45 \mathrm{ff}$.

157 Beachtung verdiente auch $P s 52$ in der vom Vf. entwickelten Sicht, Der 52. Psalm. Studien zu seiner Einordnung.

158 Wir sprechen von ihr in dem bei STECK umrissenen Sinn, Strömungen theologischer Tradition im Alten Israel $306 \mathrm{ff}$.

159 GUNKEL, Einleitungen. Die Propheten als Schriftsteller und Dichter XLVI.

160 Siehe oben in Ziffer 4.1 !

161 Man vgl., was GUNKEL zur Charakterisierung des Stils dieser Rede vermerkt, Einleitungen. Die Propheten als Schriftsteller und Dichter XLVI-XLVII! 
Name. Stattdessen kommt, nicht minder charakteristischerweise, ein Bild, ein Symbol (das des Zepters) zur Verwendung; einerseits, wie gesagt, Concretum pro abstracto und eine Art von Veranschaulichung; andererseits aber auch, inmitten der Zukunftsansage, ein Moment der Verhüllung. Da ist - der Seitenblick drängt sich auf - so wie beim prophetisch geprägten BileamOrakel formuliert: "... es erhebt sich ein Zepter 162 aus Israel ...", Num 24,1763. Ist das nicht, alles in allem, Grund genug, mit punktueller Einwirkung prophetischer Oberlieferung zu rechnen?

Indessen - nach wie vor will bedacht und berücksichtigt werden, daß Zukunftsgewißheit auch aus weisheitlichen Gründen erwachsen kann. Nach der Erfahrung und überzeugung der Weisen vollzieht sich in der Wirklichkeit menschlichen Lebens Tun-Ergehen-Entsprechung. Als von Gott eingestiftete Ordnung. Menschlicherseits nicht verfügbar und nicht in den Griff zu bekommen. Von Jahwe vielmehr zu erharren. Auch und gerade dann, wenn der widrige Anschein anficht ${ }^{164}$. Jene Entsprechung zwischen Tun (Sich-verhalten) und Ergehen wird, von Gott gewollt und herbeigeführt, letzten Endes zustande kommen, dem Augenschein in Vergangenheit und Gegenwart zum Trotz. Der Autor des Psalms, der um Vertrauen auf Jahwe wirbt, um Vertrauen darauf, daß er es vollführt, ist in dieser Hinsicht selbst gewiß. So sehr, daß er unbedingt den Vollzug der Entsprechung ansagt.

Gleichwohl erscheint es nicht adäquat, hier von Vertrauensäußerung oder zuversichtlichem Bekenntnis zu sprechen. Denn, was wir vermerkten, bleibt gültig: Die Außerung des Psalmisten in $v$. 3a läßt Stilmerkmale erkennen, die der prophetischen Weissagung eignen. Also kündigt er zwar aus sapientialer Substanz, tut es aber in prophetischem Stil. Ein Befund, der nicht

162 Im hebräischen Grundtext Šbaet - wie an der uns interessierenden Stelle.

163 Zur geheimnisumwittert verhüllenden Stilart siehe auch Anm. 106.107!

164 Anm. 133.135! Beachtenswert Ps 37! 
halb so schwierig ist, als es prima vista erscheint. Denn: es fehlt nicht an Anhaltspunkten dafür, daß Weise in fortgeschrittener alttestamentiicher Zeit, während welcher die Prophetie in den Hintergrund trat, sich "neben oder an Stelle" der Propheten sahen, als ebenso inspiriert verstanden, als so erleuchtet und bevollmächtigt wie sie ${ }^{165}$. Andererseits gibt es Grund zu der Annahme ${ }^{166}$, daß der uns interessierende Psalm gerade dieser späteren Zeit entstammt. Damit wird klar, wie jener Befund zu erklären ist: 125 ist nicht nur aus eigentlicher Weisheit, ihren Erfahrungen und Oberzeugungen erwachsen, sondern auch aus Impulsen und Momenten, die auf prophetische uberlieferung zurückgehen und in der jüngeren alttestamentlichen Weisheit mit in Erscheinung treten ${ }^{167}$.

In summa: eine Einwirkung prophetischer Tradition? Ganz sicherlich ja! Allerdings - eine mittelbare! Nicht eine, die direkt und erstmalig beim Verfasser unseres Psalmes aufträfe. Vielmehr eine, die in breiterer Front auf die Weisheit trifft, auf diese in späterer Zeit, und die in ihr, wenigstens hier und dort, entsprechende Wirkung zeitigt. Eine derart entwickelte Weisheits-

165 Vf. verzichtet dieses Mal darauf, Belegtexte vorzuführen (abgesehen von Andeutungen in einer Beziehung, Anm. 167). Er verweist vielmehr auf frühere Ausführungen, vor allem in: Der 52. Psalm. Studien zu seiner Einordnung 78f; ergänzend: Werden und Wesen des 107 . Psalms 16. Vergleichenswert nicht zuletzt FOHRER, Das Buch Hiob 450/451; JANSEN, Die spätjüdische Psalmendichtung $59 \mathrm{f} .75 \mathrm{ff} .145$ sowie VON RAD, Weisheit in Israel $77 \mathrm{ff} .376 \mathrm{f}$.

166 Erinnert sei an das vorhin erlangte traditionsgeschichtliche Indiz. Anderes, von dem noch die Rede sein muß, deutet in dieselbe Richtung.

167 Ps 49 verdient als signifikantes Exempel hervorgehoben zu werden: Er ist ein spät entstandenes Weisheitsgedicht. Der in ihm spricht, neigt erklärtermaßen sein $0 \mathrm{hr}$ einer Inspiration, einem eingegebenen Spruch, v. 5a. Er ruft, infolgedessen und gar nicht verwunderlicherweise, in der Art der Propheten, v. 2. Zu allem hin kommt er aufs Vertrauen zu sprechen, einer Verkehrung desselben wehrend, $v$. $7 \mathrm{ff}$. Also ein Text, der traditionskritisch gesehen unserem Psalm an die Seite zu rücken ist! 
tradition ist sichtlich der Boden, in dem unser Text verwurzelt und aus dem er erwachsen ist 168 .

\section{1 .3}

Landnahmetradition

Der Umstand, daß in v. 3a vom "Landlos der Gerechten" die Rede ist, vom gôrăl hășsădîqîm, ist kaum ein zureichender Grund für die Annahme, da habe auch die überlieferung von der Landnahme, der Landgabe, in unmittelbarer Weise eingewirkt ${ }^{169}$. Nur indirekt und aus einiger Ferne hat sie Einfluß gehabt und einen Akzent setzen lassen. Dieser deutet - mehr en passant - an, das Ergehen der Gerechten in der Folge ihres Tuns und Lassens verwirkliche sich nicht freischwebend, sondern auch und gerade auf der Ebene des durchs Los zugestandenen Teils am verliehenen Land. Keine Frage: das Verständnis der Teilhabe am Land und der Verteilung desselben durchs Los, gôral, ist von der Landnahmetradition her bestimmt gewesen und auf die Länge der Zeit auch geblieben 170 . Insofern ist eine Fernwirkung auch dieser überlieferung im Spiel. Präzisierend ist wieder - so wie im vorigen Abschnitt - hinzuzubemerken, die Tradition von der Landgabe habe nicht erst und unmittelbar den Dichter unseres Psalms beeinflußt, sondern zunächst und breitergreifend die Weisheit. Darauf lassen sehr ausgeprägt deutliche Parallelen zu 125,3a im weisheitlichen Psalmgut schließen; vor allem in Ps 37, des weiteren in Ps 25,12.13, einem sapiential orientierten Element ${ }^{171}$. In bezeichnender Streuung tauchen hier dieselben Gedanken auf: Die Gerechten, ganz ausdrücklich sie, besitzen das Land, wohnen immerzu in ihm, Ps 37,29. Die Jahwe vertrauen und Gutes tun, sollen folglich das

168 Ps 49 und, nicht zu vergessen, Ps $52 \mathrm{mit} i \mathrm{hm}$.

169 Insofern ist nichts auszusetzen an LAUHA, Die Geschichtsmotive in den alttestamentlichen Psalmen $99 \mathrm{ff}$, auch nicht an JASPER, Early Israelite Traditions and the Psalter, in: VT $17,1967,50 \mathrm{ff}$.

$170 \mathrm{Vg}$ l. etwa DE VAUX, Das Alte Testament und seine Lebensordnungen, I, $264 \mathrm{ff}$ sowie DALMAN, Arbeit und Sitte, II, $39 \mathrm{ff}$ !

171 Vgl. hierzu etwa KRAUS 351! 
Land bewohnen, Ps 37,3. Die Nicht-Gerechten, so wird kontrastweise klargestellt, werden aus dem Lande vertilgt, Ps 37,9.10. Das einzig mögliche Fazit: die genannten Gedanken aus der Landnahmetradition haben zunächst einmal in der überlieferung der Weisheit Eingang gefunden. Nach den spät entstandenen akrostichischen Texten Ps 25 und 37 zu urteilen, wahrscheinlich entsprechend spät. Also abermals in der jüngeren Weisheit. In ihren Bahnen und geleitet durch sie kam unser Psalmist zu der hier verhandelten Wortwahl, zu der vom "Landlos der Gerechten".

Im Rückblick auf die stilkritische Analyse ${ }^{172}$ bleibt schließlich noch eins zu bemerken: In einem Zusammenhang, der zur Verwendung von Tropen neigt ${ }^{173}$, ist nicht zu bezweifeln, daß der Gerechten "Landlos" pars pro toto Erwähnung findet. Das Zepter des Frevels, das auf dem Lande lastet, trifft mit diesem zugleich seine Besitzer, verwehrt ihnen, auf der Lebengrundlage ihrer Fluren das Ergehen des Heils, das ihrem Tun entspricht, zu erfahren. Die Erfüllung der Zusage $v$. 3a entlastet entsprechend nicht nur die Landlose der Gerechten. Vielmehr auch diese in ihrem ganzen Ergehen. Ergo ist klar: der Psalmist meint, wenn er vom Landlos spricht, zugleich das Los der Gerechten überhaupt und total. Er verwendet das aus der überlieferung der Weisheit und letztlich aus der der Landgabe übernommene Wort gôral in einem auch erwe iterten $\operatorname{sinn}^{174}$.

172 In Ziffer 4.1 .

173 BÜHLMANN / SCHERER, Stilfiguren der Bibel $63 \mathrm{ff}$. 174 Vergleichenswert der Gebrauch des Synonyms helaeq in Ijob
31,2 . 
6.1 .4

Jerusalemer Kulttradition, Teil I:

Königstradition 175

Wirkt nicht auch sie in der eben verhandelten Wendung nach, genauer, im Ausdruck "Zepter des Frevels", Šebaet haraešăc176̆? Mit einem ihrer zentralen Motive scheint sie Ausgangspunkt bei dieser Formulierung gewesen zu sein. - Nach einem Königspsalmtext wird das Zepter vom Zion ausgereckt. Das Zepter des davidischen Königs. Soweit, wie Jahwe es will, Ps 110,2. In einem anderen Königspsalmstück wird ausgedrückt, was das Zepter davidischer Königsherrschaft zu sein hat: "Zepter der Gerechtigkeit", Šebaet mî̌sor, Ps 45,7. Der es in Händen hat, liebt das Recht, die Gerechtigkeit, haßt andererseits den Frevel, Ps 45,8. Sein Zepter ist Gegenstück zum šebaet haraešac, steht zu diesem im Gegensatz. - Nachgerade ist unwahrscheinlich, daß die Wortwahl "Zepter des Frevels", šebaet haraesuac, in Ps 125,3a getroffen worden sein sollte in Unkenntnis jener Bezeichnung, die dem idealen Zepter davidischer Herrschaft gilt. Es hat mehr für sich, daß unser Psalmist, an ihr orientiert, der Auffassung gewesen ist, das jetzige Regiment sei ein schierer Kontrast zum davidischen Ideal. Es stehe nicht im Zeichen des šebaet mî̌or, sei vielmehr Pervertierung desselben. - So hat es Plausibilität, daß der in der Weisheit verwurzelte Verfasser unseres Gedichts punktue 11 auch von der Königstradition bestimmt gewesen ist. - Unvereinbar mit seiner Weisheitlichkeit ist ihm dies sicherlich nicht erschienen. Denn auch in der Weisheitsüberlieferung sind, ererbt aus staatlicher Zeit, "Königssprüche" erhalten geblieben, die ein affines Ideal der Königsherrschaft bezeugen, Spr 16,12ff u.ö.177. - Was Wunder, daß dem so ist! Denn schließlich sind Weisheit und Königtum im Jerusalem der staatlichen Ára aufs

175 Mit STECK, Friedensvorstellungen im alten Jerusalem $9 \mathrm{ff}$. Ebd. Hinweise auf primäre und sekundäre Literatur. Vgl. andererseits auch WILDBERGER, Jesaja 1597 !

176 Zur textkritischen Abklärung Ziffer 2.3.

177 Ergänzende Angaben bei GESE, Lehre und Wirklichkeit in der alten Weisheit 36 . 
engste benachbart gewesen! - Dieser Umstand scheint aber im vorliegenden Fall die Annahme nicht begründen zu können, unser Psalmist sei via Weisheit zur Formulierung "Zepter des Frevels" gekommen. Die Anklänge an Ps 45,7.8 bestärken vielmehr in der Vermutung, eine Reminiszenz an dieses oder ein entsprechendes Element der Königstradition sei bestimmende Anregung gewesen. Natürlich nicht dazu, eine Restitution des Königtums zu erwarten. Das Zukunftswort 125,3 1äßt nicht die Spur einer davidischen Hoffnung erkennen. Es versteift sich nicht auf eine Angabe, wie es dazu kommen werde, daß das frevlerische Zepter weicht. Es beschränkt sich darauf, via negationis zu künden: "nicht wird (lasten) bleiben ..."

\section{1 .5}

Jerusalemer Kulttradition, Teil II:

\section{Zionstradition}

Klar genug ist, daß auch sie ihre Spuren eingedrückt hat. Dort, wo der Psalm Vergleiche anstellt: in v. 1 und 2. Die Bezugnahmen auf Zion, der nie ins Wanken gerät, und auf Jerusalem, das umhegt ist, heben auf zur Zionstradition gehörende Motive ab. Es kann hier nicht darum gehen, die Gesamtkonzeption, die dieser überlieferung zugrunde liegt, im einzelnen darzutun. Dies ist anderwärts und schon öfter geschehen ${ }^{178}$. Es genügt hervorzuheben, daß Zion/Jerusalem als erwählte Wohnstatt Jahwes 179 und hierdurch als Zentrum kosmischer Ordnung und stabilisierten Lebensraums 180 so festgemacht sind, daß sie durch nichts und niemals ins Wanken gebracht werden können, Ps 46.48.76 u.ö. Im erstgenannten Zions-

178 Beispielsweise durch HAYES, The Tradition of Zion's Inviolability, in: JBL 82, 1963, 419ff. Umfassender durch STECK, Friedensvorstellungen im alten Jerusalem. Detailliertere Hinweise ebd. Der Vf. selbst ist dem Komplex vor kurzem schon einmal nachgegangen, in: Weisheitlich-kultische Heilsordnung, in den dortigen Ziffern 7.1.3 und 7.1.4.

179 ROHLAND, Die Bedeutung der Erwählungstraditionen $119 \mathrm{ff}$; METZGER, Himmlische und irdische Wohnstatt Jahwes, in: UF $2,1970,139 \mathrm{ff}$.

180 STECK, Friedensvorstellungen 16-25; CLEMENTS, Temple and Land, in: TGUOS 19, 1962, 16-28. Beachtlich auch etwa WRIGHT, The Temple in Palestine-Syria, in: BA 7, 1944, 66-77. 
lied steht, bezogen auf Jerusalem/Zion, das bündige Wort, weil Jahwe in ihnen präsent sei, wankten sie nicht, bă l-timmôt ${ }^{181}$, Ps 46,6. Daß deshalb dort Schutz zu erlangen sei, wird besagter Psalm zu betonen nicht müde. Bereits hierdurch ist hinlänglich klar, daß es zentrale Gedanken der Zionsüberlieferung sind, die auf unseren Psalmdichter einwirkten. - Frappant, daß er nicht den Versuch unternimmt, sich ihnen zu entziehen. Er läßt sich vielmehr, wiewohl in der oberlieferung der Weisheit verwurzelt, von Zion/Jerusalem faszinieren. Er steht da und kontempliert und entdeckt Affinitäten zwischen Zion/Jerusalem und dem, was weisheitliche Einsicht lehrt: Wer auf Jahwe vertraut, genauer, darauf, daß dieser die Entsprechung zwischen Tun und Ergehen Widrigem zum Trotz verwirklicht, der ist so fundiert wie Zion, so umhegt wie Jerusalem; er wankt so wenig wie diese. Der sapientiale Psalmist hat in seinem Erkenntnisstreben und pädagogischdidaktischen Eifer keine Berührungsängste gegenüber der so anderen Tradition. Er rezipiert einige ihrer Elemente, um mit ihnen vergleichend weisheitliche Wahrnehmungen beizubringen. Es geht ihm mitnichten darum, die Zionstradition zu forcieren. Er setzt sie nur eben voraus und stellt, wohl zu Recht, in Rechnung, daß viele von denen, die er anspricht, auf dem Boden derselben stehen oder mit ihren Motiven vertraut sind. Sein Impetus geht darauf aus, auf den Boden der Weisheit zu holen und - in ihrem Sinn - Vertrauen auf Jahwe zu wecken. Der Verfasser des primären Texts setzt nicht-auf das Heil, das der Jerusalemer Kult erschließt. Er wirbt darum, die heile Existenz, die, die nicht wankt, im weisen Vertrauen auf Gott und die Durchsetzung seiner der Wirklichkeit eingestifteten Ordnungen zu erwarten und zu erlangen. Er wirbt nicht nur; er betet und bittet auch darum.

6.1 .6

Rückblick und Auswertungen

Allerlei Traditionen sind bei der Abfassung des ursprünglichen Textes zum Tragen gekommen. Was natürlich und nicht verwunderlich

181 Subjekt: die Gottesstadt Jerusalem; im Hebräischen femininum. 
ist. Wer ist sich schon immer - analysierend, sortierend - der diversen Einwirkungen bewußt, denen er unterliegt? Es liegt im gegebenen Falle jedoch auf der Hand, welche überlieferungen mehr beiläufig einwirken. Zum einen die Zionstradition. Sie ist mit ihrem Haftpunkt zusammen offensichtlich so nah, daß sie sich "imponiert". Wenigstens als Möglichkeit, zu veranschaulichen und zu vergleichen. Eine Berücksichtigung ihrer Substanz findet nicht im mindesten statt. Zum anderen ist ähnlich beiläufig ein Element aus der Königstradition. Es fungiert nur als Anregung für die kritische Wendung "Zepter des Frevels". Substanz auch aus dieser uberlieferung wird nicht aufgenommen. Der Wortlaut des Textes läßt nirgends erkennen, davidische Hoffnung beflügle. Zum dritten wirkt die oberlieferung von der Landgabe ein. Nur mittelbar und in einem Punkt. Zum vierten prophetische Tradition. Nicht minder indirekt und auf eine Stelle beschränkt. Gleichwohl mit einigem Effekt: Der Psalmist sagt charismatisch bevollmächtigt Künftiges an. Im wesentlichen dennoch als Weiser: Im ganzen und einzelnen ist er von nichts so durchdrungen wie von den Einwirkungen sapientialer Tradition. Auch die Erwähnung der Teilhabe am Land und der Einschlag prophetischer Art gehen auf diese zurück. Entsprechende Elemente haben als Bestandteile entwickelter, jüngerer Weisheit Wirkung erzielt. So gesehen ist trotz der Vielzahl involvierter Traditionen klar: der primäre Bestand unseres Psalms ist im wesentlichen weisheitsbestimmt. 125 ist der Reihe sapientialer Texte im Psalter zuzurechnen.

Auswertungen bieten sich an: Vorab und vor allem die unter dem Gesichtspunkt der Frage, wann der primäre Bestand entstanden sein kann. Selbstredend erst, nachdem bestimmte Entwicklungen vollzogen waren: So der Rückgang der Prophetie und korrespondierend das Eintreten der Weisen an ihrer Statt unter übernahme prophetischer Funktionen und Formen ${ }^{182}$. Anzeichen einer Desintegration der Prophetie sind nach der frühen Perserzeit wahrzunehmen, in der ersten Hälfte des 5. Jh. v. Chr. ${ }^{183}$. Da es

182 Ziffer 6.1.2.

183 Siehe etwa GOTTWALD, A Light to the Nations $437 \mathrm{ff}$; $\mathrm{KOCH}$, Die Profeten, II $190 \mathrm{f}$. 
seine Zeit gebraucht haben wird, bis sich Weise (und andere ${ }^{184}$ ) im Vakuum neuorientiert hatten, ist der Stand der Dinge, den 125 voraussetzt, wohl kaum vor der zweiten Hälfte des 5 . Jh. erreicht gewesen. Mithin bleibt schwerlich anderes übrig, als den Psalm aus der alttestamentlichen Spätzeit, der fortgeschrittenen Perserepoche oder der Ära des Hellenismus herzuleiten. Ps 49, mit dem sich unser Text in mehr als einem Punkte berührt, wird entsprechend spät datiert. Auch das Weisheitsgedicht Ps 37 , nach dem die auf Jahwe vertrauenden Gerechten das Land besitzen werden, gilt - im Einklang mit den bisherigen Eindrücken - als ausgesprochen spät. Nicht zuletzt weist die in unserem Text lebendige Tendenz, die Gerechten von den andern zu sondern, in die Spätzeit des Alten Testaments, aus der auch Ps 1 herrührt ${ }^{185}$. Somit deutet etliches in der Substanz des ursprünglichen Bestands in überzeugender Konvergenz auf den Zeitabschnitt, an den wegen sprachlicher Eigenheiten 186 ohnehin schon des öfteren gedacht worden ist. Das Ergebnis ist wohlfundiert, freilich nicht gerade eng eingrenzend: Der ursprüngliche Text unseres Psalms ist in der fortgeschrittenen Perserzeit oder in der Ära des Hellenismus verfaßt worden.

Damit ist auch klar, daß die Formulierung "Zepter des Frevels" nicht abhebt auf einen davidischen König, sondern auf einen fremden Herrscher. In den Sog seines Regiments sind schon etliche in Israel geraten, drohen nach $v$. 3b gar Gerechte gezogen zu werden. Unser Psalm wirkt der Gefahr entgegen, weckt in v. 3a neue Zukunftserwartung. Er zündet sie aus sapientialer Substanz. Was so ungewöhnlich, wie es zunächst erscheint, bei genauerer Umschau nicht ist 187 .

184 Siehe etwa PETERSEN, Late Israelite Prophecy!

185 Siehe oben, am Ende der Ziffer 6.1.1!

186 Anm. 121! "... dieser Ps. einer der jüngsten ..." DELITZSCH 747 u.a. mit inm.

187 Der Vf. verweist auf seine Betrachtung zu 131,3, in: Wider die Hybris des Geistes 102. Hervorgehoben zu werden verdient, daß auch Ps 37 eine offnung sapientialen Denkens "zur Zukunft hin" beobachten läßt. Nicht von ungefähr die eschatologische Kommentierung dieses Psalms in 4QpPs 37 ! ALLEGRO, Qumrân Cave 4,43ff. 
Noch eine andere Auswertung bietet sich an. Eine unter dem Gesichtswinkel der Verfasserfrage: Nachgerade steht fest, daß, der den Psalm erschuf, ein Weiser gewesen ist. Bot sich ihm, als er verglich und veranschaulichte, nichts mehr als Jerusalem/ Zion an, so spricht dies dafür, er habe sich, als er verfaßte, im Weichbild derselben befunden. Eine Annahme, die sich auch sonst nahelegt. Denn der Traditionsstrom der Weisheit ist, auch in der Ara nach dem Exil, hauptsächlich und mehr als sonstwo im Jerusalemer Bereich geflossen. In geistiger Nachbarschaft zum zweiten Tempe ${ }^{188}$. Verfasser ist also ein Weiser aus der Jerusalemer Region der alttestamentlichen Spätzeit gewesen. Womit einerseits viel und andererseits wenig gesagt ist. In sozialer, soziologischer Hinsicht ist jedenfalls nichts ausgemacht - und wohl auch nichts zu ermitteln. Denn dem Eindruck ist Rechnung $z u$ tragen, daß die Einstufung "Weiser" keine Zuordnung zu einem Berufsstand ist ${ }^{189}$. Schließlich fehlt es an Anhaltspunkten, die anzunehmen erlaubten, unser Autor sei Weisheitslehrer gewesen ${ }^{190}$. Allenfalls allgemein, nicht im berufsständischen Sinn, könnte er Lehrer genannt werden. Denn soviel läßt der Text wohl erkennen: daß da einer, auf Grund besseren Wissens und tieferer Weisheit, andere belehrt. Auch, nicht etwa ausschließlich.

Dieses zu Verfasserfrage und Zeitansatz! Es ließ sich, einleuchtenderweise, am besten und rationellsten im Anschluß an die Traditionskritik sagen. - Über den Auswertungen dieser Art ist allerdings nicht zu vergessen, daß es noch abschließender traditionskritischer Erhebungen bedarf:

188 STECK, Strömungen theologischer Tradition im Alten Israel 311 .

189 WHYBRAY, The Intellectual Tradition in the 0ld Testament $1-54$.

$190 \mathrm{Vgl}$. mit den Uberlegungen des Vfs. in: Wider die Hybris des Geistes $83 \mathrm{f}$. Zur Erörterung der Frage, von wann ab mit Schulen zu rechnen ist, vgl. man die letzten Stellungnahmen, einerseits GOLKA, Die israelitische Weisheitsschule oder "des Kaisers neue Kleider", in: VT 33, 1983, $257 \mathrm{ff}$, andererseits LEMAIRE, Sagesse et écoles, in: VT $34,1984,270 \mathrm{ff}$ ! 
6.2

Beim sekundären Bestand

Es hat nicht viel Sinn, die Glosse jošeb zwischen v. 1 und $2^{191}$ traditionskritisch auszuloten. Die Explikation, nicht Jerusalem, nein, die Bewohnerschaft der genannten Stadt sei umhegt, geht sicherlich nicht über den Horizont der Zionstradition hinaus, hat aber doch weniger mit dieser als mit der Pedanterie des Glossators zu tun.

Was die eingefügte Formel "von nun an, fortan", v. 2c, anbelangt, so geht es nicht an, sie als Sondergut einer einzigen Tradition zu bewerten ${ }^{192}$. Wohl deuten ein paar Belege - vor allem Ps 115,18 und $M i$ 4,7 - darauf hin, daß die Stereotype in der Jerusalemer Kultsprache geläufig geworden sein muß ${ }^{193}$. So wäre immerhin klar, daß auch diese Erweiterung vom Jerusalemer Kult, genauer, von der in ihm gängigen Sprache unschwer ableitbar ist. - Mi 4,7b und Ps 121,8 lassen zudem den Gedanken aufkommen, die Versicherung "von nun an, fortan" sei gerade auch dann abgegeben worden, wenn es sich um Inschutznahme drehte ${ }^{194}$. Dies würde zur Erklärung gereichen, wie es zu der Einfügung kam, die dem Gedanken, von Jahwe beschützt zu sein, zusätzlichen Nachdruck beilegte.

Was die am Schluß angefügte Wendung šalôm cŭl-jiśra ${ }^{2} e 1, v .5 c$, betrifft ${ }^{195}$, so braucht nicht erst lange ermittelt zu werden, zu welcher Tradition sie gehört: Sie nimmt auf die Institution der priesterlichen Segnung 196 Bezug. In der Spätphase der alt-

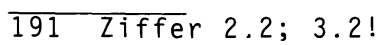

192 Anm. 74.76!

193 Zum letztgenannten Element siehe WOLFF, Dodekapropheton. Micha 86.90 .96 !

194 Auch in diesem Zusammenhang noch einmal WOLFF, Dodekapropheton. Micha 96.

195 Ziffer 3.4!

196 WESTERMANN, Der Segen in der Bibel 45ff; WEHMEIER, Der Segen im Aiten Testament 216f; SEYBOLD, Der aaronitische Segen $55 \mathrm{ff}$. 
testamentlichen Zeit, an die hier gedacht werden muß, kann nur die Segnung anvisiert sein, die im Kult auf dem Zion geschieht. Die, die durch Priesterwort und -handlung von der Stätte vor dem Altar 197 und vom Hause Jahwes her ${ }^{198}$ der gottesdienstlichen Gemeinde im Vorhof des Tempels zuteil wird. Aufschluß und Anschauung vermittelt Ps 118,26: "Gesegnet, wer einzieht, in Jahwes Namen! Wir (die amtierenden Priester) segnen euch (die im Vorhof Versammelten) von Jahwes Hause her."

Es ist nicht schwer zu erweisen, daß der Akt solcher Segnung šalôm zu verwirklichen hatte. Der Wortlaut des a aronitischen Segens, Num 6,24-26, der im nachexilischen Kult auf dem Zion gebräuchlich geworden sein wird, will - zusammen mit Schutzgewährung und Gnadenerweis - vor allem šalôm bewirken, šalôm

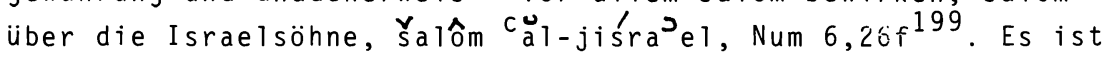
überhaupt keine Frage - das Schlußwort im Anhang unseres Psalms lenkt den Blick auf nichts anderes als den Akt der Segnung im Jerusalemer Heiligtumskult, der im wesentlichen šalôm-Setzung wollte und entsprechend im Wort und in der Sache salôm Schwerpunkt. und Klimax hatte 200 . Die so nachdrückliche Erwähnung des zugewandten, leuchtenden Jahwe-Antlitzes, Num 6,25f, läßt be alledem deutlich werden, daß die Šalôm-setzende Segnung als Wirkung der Zuwendung und Gegenwart Jahwes gilt, als Folge der den Kult auf dem Zion entscheidend ermöglichenden Theophanie ${ }^{201}$.

197 Siehe (Lev 9,22;) 1Kön 8,54ff sowie WEHMEIER, Der Segen im Alten Testament $216 \mathrm{f}$ !

198 HARAN, Priestertum, Tempeldienst und Gebet $143 \mathrm{f}$.

199 SEYBOLD, Der aaronitische Segen. Insbesondere beachtenswert $19 \mathrm{ff} .23 .39 \mathrm{f} .43 \mathrm{f} .50 .63 .65 .67 \mathrm{f}$.

200 Vergleichenswert auch Ps $24,3.5 ; 128,5.6 ; 134,3$.

201 Vergleichenswert MOWINCKEL, Religion und Kultus $52 \mathrm{ff}$; CLEMENTS, God and Temple. The Idea of the Divine Presence in Ancient Israel, insbesondere 63-76, nicht zuletzt auch des Vfs. Hinweise auf den Zusammenhang zwischen Jahwes panîm und der kultischen Theophanie, in: Herkunft und Geschichte der ältesten Sinaitraditionen $119 \mathrm{ff}$, dazuhin DURHAM, šalôm and the Presence of God, in: FS DAVIES 272 293. 
So wird klar: die Hinzufügung $125,5 c$ hebt auf die Segnung und mithin auf die kultische Theophanie ab, auf das Herzstück und zentrale Geschehen im Zionsfestkult. Die Zugehörigkeit zur Zionstradition könnte intensiver überhaupt nicht sein.

Es bedarf kaum noch der Erwähnung, kann freilich auch nicht ganz übergangen werden, daß šalôm, schon seit vorisraelitischen Zeiten, speziell mit Jerusalem zu tun hatte ${ }^{202}$. Schließlich verlautet das Wort, einigermaßen unüberhörbar, im Namen der heiligen Stadt. Ein Umstand, der durchaus bewußt sein konnte, wie an den Wortspielen zu sehen, die Ps 122,6-8 anstellt: Šalôm, der umfassende Zustand unversehrten Wohlergehens, geht gerade und ganz speziell von Jerusalem-Zion aus ${ }^{203}$. Nachgerade ist eklatant: der sekundäre Schluß unseres Psalms bezieht sich auf die Zionstradition, sogar auf ihren zentralsten Bestand.

Was endiich die Oberschrift anlangt, die Kennzeichnung "Wallfahrtslied"204, so genügt die Explikation, gemeint sei, im vorliegenden Falle wie bei jedem Text in der Sammlung Ps 120-134, ein Zionswallfahrtslied. Der Vermerk ordnet dem Zionstraditionsbereich zu. Er ist, in dieser Funktion, ganz selbstverständlich ein oberlieferungselement desselben.

So 1 äßt sich zusammenfassen: Was wesentlich ist am sekundären Bestand, resultiert aus der Zionstradition und verklammert mit ihr. Die Formel "von nun an, fortan" ist dem Repertoire ihrer geprägten Sprache entnommen, wiewohl sie verbreiteter gebraucht worden ist. Wichtiger noch: die Oberschrift zeigt, der folgende Text sei auf Zionswallfahrten verwendungsgeeignet; nicht nur das -

202 Siehe JOHNSON, Sacral Kingship in Ancient Israel 46; PORTEOUS, Jerusalem-Zion: the Growth of a Symbol, in: Living the Mystery $97 \mathrm{ff}$; STOLZ, Strukturen und Figuren im Kult von Jerusalem $204 \mathrm{ff} .216 \mathrm{ff}$; STECK, Friedensvorstellungen im alten Jerusalem $26 \mathrm{f}$, nicht zuletzt etwa auch GRAF REVENTLOW, Friedensverheißungen im Alten und im Neuen Testament, I, 103f!

203 Vgl. etwa auch noch Ps $72,1.3 .7$ !

204 Ziffer 3.1 ! 
auch zugelassen und anempfohlen. Die Wendung am Schluß rückt den Kultakt der Segnung, Klimax im Geschehen auf Zion, in den Blickpunkt der Aufmerksamkeit. Anfang und Schluß stellen einen von Haus aus sapientialen Psalm in zionskultische und-theologische Bezüge.

Um auch hier die "Verfasserfrage" mit zu beantworten: die Beiträger des Sekundären sind, natürlich entsprechend spätnachexilisch, im Zionstraditionskreis zu suchen. - Wahrscheinlich wird sein, daß es deren mehrere waren. Denn die Glosse jošeb, v. 1/ v. 2, läßt in der ihr eigenen Art auf einen anderen Urheber schließen als der superskribierte Sammlungsvermerk. Die Bezugnahme auf den Akt der Segnung kehrt in den Texten der Sammiung nicht annähernd so mechanisch und gleichförmig wieder wie besagter Vermerk. Also wird sie auch schwerlich von ein und derselben Hand stammen. Ob der Einschub der Formel, v. $2 c$, mit der Segnungsbezugnahme, v. 5c, zusammengehört, ist schwer zu entscheiden ${ }^{205}$. Wie immer - es sind mehrere, die erweiterten! Da dem so ist, scheint es tunlich zu sein, die zutage tretenden Ansätze redaktionskritisch auszuziehen.

205 Der aaronitische Segen, der Šalôm-Setzung und Schutzgewährung verbindet, Num 6,24.26, könnte zu erwägen geben, ob nicht, der šalôm erwähnte, zugleich die Gedanken der Inschutznahme durch Jahwe, 125,2a.2b, zu unterstreichen für notwendig hielt. Vgl. Ps 121,7.8! Sicheres läßt sich nicht sagen! Bedenkenswert immerhin auch $1 \mathrm{Chr} 17,27$ und $z$. St. HORST, Segen und Segenshandlungen in der Bibel 193. 

7

Redaktionskritik

Das Kennwort "Wallfahrtslied"206 fixiert den von Hause aus weisheitlichen Psalm in der Zuordnung zum Zionsfestkult. Es gibt zu erkennen, er habe hier, in Vorstadien zu diesem, beim Vollzuge der Wallfahrt zum Zion, Aufgaben zu erfüllen. - Dieser Sachverhalt muß nicht bedeuten, der Psalm sei durch diese Indienstnahme seiner ursprünglichen Verwendung entzogen worden. Die Möglichkeit läßt sich nicht ausschließen, der Primärtext des Psalmes könnte, unberührt durch die neue Verwendung, zugleich in der originären Weise weitergebraucht worden sein; von da an also dual, in zwei verschiedenen Kontexten 207.

Es ist nicht wahrscheinlich, daß die Verpflanzung in den neuen Horizont erst durch die Redaktion erfolgte, die den Sammlungsvermerk davorschrieb. Vielmehr dürte diese nur noch besiegelt und, nicht zu vergessen, angezeigt haben, was sich voraufgehend eingebürgert hatte: die Praxis nämlich, 125 mit Bezug und im Blick auf den Zionskult zum Zuge kommen zu lassen. Im Zusammenhang mit der Entstehung dieser Praxis ist der Passus v. 5c hinzugefügt worden. Als Brückenschlag sozusagen zu dem šalôm-setzenden Akt der Segnung, der zusammen mit der Theophanie, welche diesen ermöglicht, Herzstück des Festkultes war.

Was hat zu der Praxis, unseren Psalm so zu nützen, geführt? Wie es scheint, so ungefähr dasselbe Empfinden, das auch schon Anstoß gewesen ist für die Schaffung des primären Bestandes: das Empfinden, es klaffe zwischen dem Kulterleben und der akultischen, alltäglichen Wirklichkeitserfahrung ein Hiatus. Wo blieb denn im Alltag des Lebens die šalôm-Wirkung kultischen Segnens? War da nicht - Kult hin oder her! - "das Zepter des Frevels" bestimmend, so lange schon und so sehr, daß es immer mehr in seinen Bann schlug, daß es selbst bis dahin Gerechte

206 Anm. 68!

$207 \mathrm{Vgl}$. des Vfs. Erwägung in: Werden und Wesen des 107. Psalms $97 \mathrm{ff}$ ! 
zu versuchen begann? War nicht das Medium Kultus dabei, in einem Grade fragwürdig zu werden, daß es neuer Vergewisserung bedurfte, solcher außerkultischer Art?

Es scheint, daß unser Psalm - er selbst, sein primärer Bestand, und nicht etwa erst die Redaktion - aus der Spannung dieser Fragen erwuchs; "nachkultisch" sozusagen ${ }^{208}$; aus einem nicht mehr kultischen, im gegebenen Falle weisheitlichen Zusammenhang. Abseits vom Kult und unabhängig von ihm hat ein Weiser den Versuch unternommen, die Verunsicherung abzubauen, die im Widerstreit der Erfahrungen sich aufgetürmt hatte. Er deduzierte, wie gesagt, aus der weisheitlichen Grundüberzeugung, es müsse und werde, der von Gott eingestifteten Ordnung der Dinge gemäß, zur Entsprechung von Tun und Ergehen kommen. Es gelte, in diesem Sinn auf Jahwe zu bauen. Wer ihm vertraue, der sei schon und bleibe, trotz widriger Erfahrungen, so stabil wie der Zion dastehe, im Heil, v.la.lb. Der sapientiale Psalmist ist quasi-prophetisch gewiß, weiß sich zum vergewissernden Zuspruch ermächtigt: Was irritiert -, was anficht und versucht, wird nicht bleiben, v. 3a.3b. Vertrauen und Gewißheit schließen nicht aus, die Verwirklichung des Heils, besagter Korrespondenz zwischen Tun und Ergehen, mit Bitte und Wunsch zu erflehen, v. 4a-5b. Hier wird alles, was akultisch möglich erscheint, zum Versuch gebündelt, jenen Hiatus zu überwinden.

Um nachgerade zu den Redaktionen zurückzukommen: es scheint, daß in der Folge im Kreis der Kultfunktionäre auf Zion die Einsicht herangereift ist, es könnte auch für den Festkult selbst am dienlichsten sein, den Hiatus zwischen kultischem Erleben und akultischer, alltäglicher Erfahrung ernstzunehmen und ihm auch vom Zionskult her - entgegenzuwirken. Ganz einfach so, daß man sich den um Vergewisserung bemühten Psalm zu eigen machte. Warum sollte sich die - sozusagen von der anderen Seite - von der Weisheit ausgehende Bemühung nicht nutzen lassen, um die Bereitschaft und Fähigkeit zu echterer Akzeptanz des Festkults und seiner Segnung zu verbessern oder neu zu erwecken? Wer sich

208 STOLZ, Psalmen im nachkultischen Raum, $9 \mathrm{ff} .18 \mathrm{ff}$. 
durch 125 zum Vertrauen auf Jahwe bewegen und vergewissern ließ, was da im Alltag störe, werde beseitigt, mußte ja disponierter werden, auch wieder das vom Kult vermittelte Heil wahrzunehmen. Uberlegungen solcher Art - im Verein mit einer gewissen Aufgeschlossenheit für Weisheitlichkeit ${ }^{209}$ - dürften die Redaktionen im vorliegenden Falle bestimmt haben. Wie könnte es anders sein, als daß weisheitsfreundiche Kräfte am Tempel zur Geltung gebracht haben, unser Psalm sei als Hilfe zur Disponierung für die Festkultteilnahme geeignet, ja, gar anzuempfehlen?

Kann es nicht auch plausibel erscheinen, irgendeiner der so Eingestellten habe, um die Akzeptanz des kultisch vermittelten Heils zu fördern, auch die überkommene überzeugung unterstrichen, Jahwe umhege Jerusalem und schütze sein Volk? Fürwahr, er tut's! "Von nun an, fortan", v. 2c! Wie sollte, wenn dem so ist, das die Glaubwürdigkeit des Kults strapazierende "Zepter des Frevels" dauern können?

Alles in allem ist festzustellen: Der Primärtext unseres Psalms, vom Verfasser erschaffen, um dort, wo der Festkult im Stich ließ, zu vergewissern, ist von Redaktoren umfunktioniert worden. Unter Belassung und Nutzung der ihm eigenen Vergewisserungstendenz. Indes - was er bis dato vikarijerend, anstelle des Festkults, erstrebte, das sollte er nunmehr subsidiär, dem Festkult zugut, erbringen. Zum Behuf der Wiederherstellung des Zutrauens zu diesem und der in ihm wichtigen Institution der šalôm-setzenden Segnung. Die außerhalb des Kults ergriffene Initiative wird innerhalb des Kults zu seiner stützung aufgegriffen und amtlich autorisiert und forciert 210 .

209 Zur Frage der Verträglichkeit von Zions- und Weisheitsüberlieferung siehe ergänzend des Verfassers Betrachtungen in: Weisheitlich-kultische Heilsordnung. Studien zum 15. Psalm, Ziffer 7.1.4!

210 Hierbei war der Umstand, daß der primäre Text die "Gerechten" von den anderen zu sondern tendierte, kein Hindernis. Schließlich war auch im Festkult nicht jeder genehm. Der Psalm hätte freilich, in seinem sekundären Gebrauch, eine Prädisponierung zum Kult mit einem neuen Maßstab betrieben, der, verglichen mit nur rituellen Vorbedingungen, eine beträchtliche Vertiefung bedeutete. 

8

Gattungskritik

Nach allem ist klar, wie abwegig es ist, den primären Bestand als Klage-oder Vertrauenslied des Volks zu bestimmen ${ }^{211}$. Einstufungen dieser Art verallgemeinern einzelne Momente des Psalmtexts - sichtlich aus dem Bemühen heraus, im Rahmen altüberkommener, konventioneller klassifikationen zurechtzukommen. Orientiert am Raster herkömmlicher Gattungen erscheint nur die Annahme möglich, da hätten sich diverse Elemente derselben zu einem "Mischgedicht" zusammengefügt: weisheitliche Lehrdichtung zum einen, prophetische Verheißung zum andern, sowie Bitte und Wunsch aus der Volksklagegattung zum dritten ${ }^{212}$. Die Feststellung einer solchen Mischung mutet als Ergebnis an, besagt aber im Grunde wenig. Am ehesten wohl noch dies, daß etliche der genannten Elemente von den ursprünglichen konkreten Situationen der jeweiligen Gattungen sich losgelöst haben müssen 213 . In der Folge wird gern und häufig von kultfreier, geistlicher Dichtung gesprochen 214 . Das signalisiert eine neue Art Psalm, gibt aber zugleich zu erkennen, eine Gattungsbestimmung im eigentiichen Sinn sei nun unmöglich geworden. Was weitestgehend den Verzicht bedeutet, im gattungsgemischten Text Allgemeines-Typisches auszumachen, das in mehr besteht als im "geistlichen" Charakter, was immer hierunter zu verstehen sein mag.

Angesichts dieses Verzichts verdient - im gegebenen Fall - ein Versuch beachtet zu werden, der jüngst publiziert worden ist ${ }^{215}$ : Es ist wohlangebracht, auch beim gattungsgemischten Psalm zu erkunden, ob er nicht, dem von e $i n$ e $r$ Gattung bestimmten Text entsprechend, in typischer Weise zum Gebrauch gekommen sein

211 Siehe Ziffer 1, im besonderen Anm. 22!

212 Siehe Anm. 27!

213 Mit GUNKEL / BEGRICH, Einleitung in die Psalmen 398.

214 So schon bei GUNKEL / BEGRICH, a.a.0. Siehe überdies etwa Anm. 25!

215 Von STOLZ, Psalmen im nachkultischen Raum $21 \mathrm{ff} .24 \mathrm{ff}$. 
könnte: im Gegenüber zu Adressaten, nicht einsam "im Kämmerlein"; mit einer typischen Intention und Funktion sowie in einer typischen Lage. - Nach den Abklärungen im vorigen Kapitel216 ist klar, daß bei Ps 125 - sowohl in seiner primären als auch in seiner sekundären Fassung - die genannten Bedingungen erfüllt sind: Er ist "Vergewisserungspsalm"217. Ein Psalm, der in der durch die Krise des Kultes bestimmten und insofern typischen Lage verunsicherte Adressaten des Heils und der Gerechtigkeit Jahwes zu vergewissern versucht. Dies - so ist zu ergänzen! in einer das Ganze umfassenden, alles durchwaltenden durchaus typischen Form: in der der Rede 218 ! Diese ist eine "vom Redenden als in der Beziehung zur Situation abgeschlossen gemeinte Artikulation ... mit der Intention ... der Anderung dieser Situation." Sie nimmt Einfluß auf den, der der Situation mächtig ist. Sie ist dabei nicht durch ihre Länge bestimmt. Vielmehr "durch die vom Redenden gewollte ... Ganzheit", "durch die Meinung des Redenden am Schluß der Rede, alles in der Situation redend Mögliche oder Zweckentsprechende zur Änderung der Situation getan zu haben"219. Ist nicht alles dies, was Rede ausmacht, in dem uns vorliegenden Psalm gegeben?

Bezugnahme auf die Situation, in welcher "das Zepter des Frevels" regiert und den Kult auf dem Zion und seinen Anspruch, Šalôm zu bewirken, desavouiert und so verunsichert und verführt, nachgerade gar die "Gerechten". Der Psalm intendiert die Anderung dieser Situation. Er sucht einzuwirken auf den, der der Situation mächtig ist: auf den die Geschichte wirkenden und lenkenden alttestamentlichen Gott. Der Psalm kann dieses nur flehentlich: in

216 Unter Ziffer 7, Redaktionskritik.

217 STOLZ, Psalmen im nachkultischen Raum 28.

218 Von einem Lied zu sprechen, ist einigermaßen voreingenommen. Wenigstens, was den primären Bestand des Psalms anbelangt. Es ist dringlich und an der Zeit, in die Analyse einzubeziehen, was Rede konstituiert. In Anlehnung an LAUSBERG, Elemente der literarischen Rhetorik, 1984 , $15 \mathrm{ff}$. Selbstverständlich ist, daß der alttestamentliche Stoff gewisse Adaptionen erfordert.

219 LAUSBERG, Elemente der literarischen Rhetorik, 15.16. 
den Gebetsformen Bitte und Wunsch, v. 4a-5b. Er kann es äußerstenfalls, indem er die Ordnung ins Bewußtsein erhebt, welche Jahwe selbst im Ablauf der Dinge will, die Ordnung der Entsprechung von Tun und Ergehen, v. 4a-5b. Bei aliedem ist klar: Gottes Gottheit begrenzt die Möglichkeiten, auf den "Situationsmächtigen" Einfluß zu nehmen. Er begrenzt sie - positiv-dadurch, daß er die Anderung der Situation bei sich selbst schon beschlossen hat. Im Wissen darum kann der Redende Zukunftsansage einsetzen, $v$. 3a. Er gebraucht auch sie, um Situationsänderung zu befördern. Dieses Mal von den menschlichen Adressaten seiner Rede her. Soviel da an ihnen liegt. Gelingt's dem Psalmisten, sie zu bewegen, ihr Vertrauen auf Jahwe, auf die Ordnung der Entsprechung von Tun und Ergehen zu setzen, so ändert sich die Lage von innen her - unter Vorwegnahme einer Anderung im Außeren: Wo Verunsicherung herrschte, kommt Vergewisserung zustande. Wer von Zukunftsansage und weisheitlicher Einsicht bewegt Vertrauen wagt, ist antizipando bereits im Heil, in so dauernder Stabilität, wie sie im Zion vor Augen steht, $v$. 1a.1b. - Läßt sich somit nicht sagen, der Verfasser des Psalms habe alles, was der Absicht der Anderung der inneren und äußeren Lage entgegenkam, so eingesetzt, daß er füglich der Meinung sein konnte, das "redend Mögliche oder Zweckentsprechende zur Anderung der Situation getan zu haben"? Ist es ergo nicht angebracht, unseren Psalm als Rede zu bestimmen, im Blick auf besagte Absicht als "Vergewisserungsrede"? Findet nicht bei dieser Art Gattungsbestimmung die ungewohnt neue Verbindung von Elementen aus verschiedenen altherkömmlichen Gattungen eine runde, überzeugende Erklärung?

Des weiteren empfiehlt sich die Annahme, unser Psalm sei nicht "Verbrauchs-", sondern "Wiedergebrauchsrede" gewesen ${ }^{220}$; m.a.w. ein Text, der von vorneherein nicht zum bloß einmaligen Gebrauche verfaßt war. Wie hätte sich auch bei der Art der Problemlage, durch die er verursacht ist, seine Absicht - die der Vergewisserung - in einer einzigen Rezitation erledigen lassen?

220 Noch einmal im Anschluß an LAUSBERG, Elemente der literarischen Rhetorik $16 \mathrm{f}$. 
Ist es nicht schwer vorstellbar, die Verheißung, das Zepter des Frevels werde nicht bleiben, habe sich alsobald, von heute auf morgen erfüllt? Ist die Wahrscheinlichkeit, es habe eines längeren Atems bedurft, nicht größer? Die Annahme hat mehr für sich, das Moment der Verheißung und die ganze Vergewisserungsrede hätten öfter geltend gemacht werden müssen, in andauernder, anhaltender Anstrengung! Schließlich findet ja auch der Vorgang sukzessiver Erweiterung 221 lediglich dann eine Erklärung, wenn wiederholter Gebrauch unterstellt wird. Die Einstufung "Wallfahrtslied" ist nicht einem nur einmal verwendeten und gleich obsolet gewordenen Psalm widerfahren, sondern einem, der lebendig geblieben ist. So erscheint es sicher: Ps 125 war, schon in seiner primären Gestalt, "Wiedergebrauchsrede", welche als solche bewahrt und gespeichert worden ist.

Durch die Oberschrift šîr hămmăca 10 t ist bezeugt, daß diese Art Rede letztlich als Lied zum Vortrag gebracht worden ist, genauer gesagt, im Sprechgesang. Für die Vergewisserungsrede aus dem Munde eines Weisen ist diese Vortragsweise wenig gemäß. Sie dürfte wohl eher gesprochenes Wort gewesen sein. Ist dies richtig, so ist zu folgern, aus der anfänglichen Rede sei ein sprechgesungenes Lied geworden. Dies scheint zu erwägen zu geben, es könnte sich hier eine Wandlung von der einen Gattung in eine andere vollzogen haben. Indes, dem ist schwerlich so. Die Änderung im Modus des Vortrags wird keine Metamorphose im gattungskritischen Sinne bedeuten. Ob gesprochen oder sprechgesungen, die Gattung "Vergewisserungsrede" dürfte sich, im wesentlichen wenigstens, durchgehalten haben. - Zu vermuten ist freilich, daß der Vortrag des Psalms nicht Sache eines Weisen geblieben ist. Im Verlaufe des Wiedergebrauchs hat der Vortragende vielfach gewechselt. Die Annahme ist kaum zu umgehen, es werde, als der Psalm als Wallfahrtslied verwendbar geworden war, nicht immer bewußt geblieben sein, daß er von Hause aus weisheitlich war. Im Verwendungskontext der Wallfahrt zum Zion dürfte er auch für solche, die nicht Weise waren, gebräuchlich geworden sein. Je-

221 Ziffer 3 und 7 ! 
doch, auch diese Weiterentwicklung berührt die Gattungsbestimmtheit nicht wesentlich.

8.1

Die Frage nach dem Sitz im Leben

Sie ist nach dem primären und sekundären Gebrauch, nach der ursprünglichen und späteren Version des Psalms gesondert zu verfolgen.

Nach dem, was sich traditions- und gattungskritisch ergab, ist klar, daß der primäre Text vom Traditionskreis und von der Warte der Weisheit aus erschaffen worden ist; offenkundig im Hinblick auf Jerusalem/Zion, v. 1a-2a, nicht aber auf der Grundlage des Zionsfestkults und seines Oberlieferungsbestands; vielmehr aus dem Empfinden heraus, dieser halte, gemessen an der Wirklichkeitserfahrung des Alltags, nicht Stich. Dies erlaubt nur den Schluß, der Primärtext sei in einem eigenständigen Außerhalb, im akultischen Milieu eines Weisen entstanden und dort dann auch zum Vortrag gelangt. Wie gesagt, nicht bloß einmal. Vielmehr, der Problemlage entsprechend, wiederholt. Zu einer Zuordnung zum Wallfahrtsfestkult, zu einer Aneignung durch Amtsträger desselben, ist es fraglos nicht gleich gekommen. Mithin kann der Sitz des primären Psalms zunächst nur akultisch gewesen sein: im Leben weisheitlicher Kreise. Da ein waches Interesse an Sonderung und Scheidung von anderen bestand, welche nicht oder nicht mehr "Gerechte" waren, v. 3b.5a-5b, wird hinzubemerkt werden dürfen, Ps 125 könnte in konventikelhaften Versammlungen sapiential Gesonnener rezitiert worden sein. - Die in Betracht zu ziehenden Versammlungen näherbestimmen zu wollen, dürfte chancenlos sein ${ }^{22}$. Was zu erschließen war, verschafft glücklicherweise auch so schon ein brauchbares Bild.

Was den hinzukommenden, sekundären "Sitz" anbelangt, so ist zugleich viel und wenig zu sagen. Viel - insofern jene überschrift,

222 Darum versucht der Vf. auch nicht, die Hypothese ins Spiel zu bringen, die er anderwärts aufgestellt hat - in: Werden und Wesen des 107 . Psalms $91 \mathrm{ff}$. 
v. 1, nicht den mindesten Zweifel $1 a ̈ \beta t^{223}$, unser Psalm sei in seiner Letztgestalt als Lied im Kontext der Wallfahrt zum Zion gebräuchlich gewesen. Wenig - insofern es schwierig bleibt, präziser zu sagen, wo und wie es beim Wallfahrten üblich war, im Sprechgesang zu psalmieren. Es ist gewiß so, daß beim Antritt der Pilgerschaft sich die früheste Gelegenheit bot, beim Einzug in die heilige Stadt die allerletzte. Auch wird in der Tat 224 als wahrscheinlich zu gelten haben, daß unterwegs, auf Stationen der Wallfahrt, Psalmvortrag möglich war. Die Rezitation unseres Psalms ist am ehesten hier vorstellbar. 125,1b-2a könnte vermuten lassen, das "Lied" sei sinnigerweise dort erklungen, wo Jerusalem und die Berge ringsum tatsächlich vor Augen waren: bei einem Halt auf der letzten Strecke des Wegs. - Es spricht nichts dafür, daß noch außerhalb der heiligen Stadt und des Tempelbezirks die Wallfahrtsgemeinde in toto den Rahmen für diesen Vortrag zu bilden vermochte 225 . Mehr für sich hat, daß 125 inmitten der Pilgergruppen, welche, noch separat, aus den verschiedenen Heimatbereichen zum Zion strebten, kurz vor diesem Ziel rezitiert wurde. Gottesdienstlich wäre dieser "Sitz" wohl zu nennen. Kultisch jedoch nur im weitesten Sinn ${ }^{226}$. Mag sein, man hebt hier am besten 227 auf eine Art gottesdienstiicher Andacht $a b$, zu welcher Wallfahrergruppen verweilten. Was zunächst in weisheitlichen Konventikeln zu bedenken gegeben worden ist, das wäre, von Amts wegen anempfohlen, in diesem weiteren sitz im Leben, weniger exklusiv, zur Vorbereitung auf die Teilnahme am Festkult, zur besseren Rezeption desselben, bedacht worden.

223 Anm. 68 und ergänzend des Vfs. Ausführungen in: Wider die Hybris des Geistes $93 \mathrm{ff}$ !

224 Mit GUNKEL / BEGRICH, Einleitung in die Psalmen 310.

225 Dazu die Bemerkungen des Vfs. in: Wider die Hybris $94 \mathrm{ff}$.

226 Zum besseren Verständnis dieser Feststellung STOLZ, Psalmen im nachkultischen Raum 7-21.

227 In punktueller Berührung mit SEIDEL, Wallfahrtslieder $8 \mathrm{ff}$. 
So ergibt sich ein einigermaßen plausibles Bild: In der Spätzeit des Alten Testaments, in der fortgeschrittenen Epoche der Perser oder der des Hellenismus 228 , als "frevlerische" Fremdherrschaft anhielt und sogar "Gerechte" zu korrumpieren drohte, war der Glaube an den Festkult auf Zion, an sein Durchsetzungsvermögen in der Wirklichkeit des Alltags erschüttert. Da verfaßte ein im Weichbild Jerusalems lebender Weiser eine "Vergewisserungsrede"229. Er tat dies in gehobener Sprache und fortentwickelter Form, konzis und pädagogisch geschickt auf Anschaulichkeit bedacht 230 . Er zog dabei alle Register, um - soweit überhaupt einem Menschen möglich - die innere und äußere Lage zu wenden. Er führte in der Art und anstatt eines Propheten eine Verheißung ins Feld 231 , aktivierte vergewissernde Momente aus weisheitlicher überlieferung und Überzeugung ${ }^{232}$ und versuchte zum Gebetsruf mitzureißen, auf daß Gott, was bei ihm beschlossen 233 und was der Entsprechung zwischen Tun und Ergehen gemäß, endlich auch vollends vollführe. Er berührt dabei eine Reihe von Traditionen ${ }^{234}$, bleibt aber im wesentlichen weisheitsbestimmt und vergewissert so, Jahwe sei noch immer heilsmächtig und gerecht; wer ihm vertraue, sei bereits, antizipando, im Heil.

In diesem Sinne wirbt und wirkt unser Psalm über den Tag hinaus. Als Wiedergebrauchsrede. Zunächst, wie es scheint, exklusiv in weisen Zirkeln. Hernach - möglicherweise zusätzlich - in entschränkterer Weise, per Sprechgesang, bei den zur gottesdienst-
228 Ziffer 6.1.6!
229 Ziffer 7 und 8 !
230 Ziffer 4.1!
231 Ziffer 6.1.2!
232 Ziffer 6.1.1!
233 Halbvers $3 a$ !
234 Ziffer 6.1-5! 
1 ichen Andacht gruppenweise versammelten Pilgern ${ }^{235}$. Im Zuge dieses sekundären Gebrauchs sind textliche Erweiterungen erfolgt; Hervorbringungen der Zionstradition; was den Zusatz am Schluß anlangt, zum Behufe des Brückenschlags hinüber zum Zionskult und seiner Segnung ${ }^{236}$. Diese spätere Verwendung der erweiterten Einheit ist nicht unautorisiert geblieben, nicht ohne ausdrückliche Billigung der zuständigen Jerusalemer Amtsträger. Auch bei ihnen hat sich die Einsicht Bahn gebrochen, der das alltägliche Leben so wenig bestimmende Festkult sei subsidiärer Unterstützung bedürtig; und diese zu erbringen sei der vergewissernde Psalm geeignet. Die Institution des Zionstempels zeigt in der Spätzeit des Alten Testaments keine Hemmung, sich vonseiten der Weisheit $\mathrm{Hilfe}$ angedeihen zu lassen. Sie bedient sich ihrer im vorliegenden Falle nicht so, daß sie das weisheitliche Gut integriert ${ }^{237}$; vielmehr so, daß sie es assoziiert und zur Vorbereitungshilfe umfunktioniert, zur Hilfe bei der Disponierung auf den Festkult.

235 Ziffer 8.1!

236 Ziffer $3.1-5 ; 6.2$ und 7 !

237 Zu dieser Art Einverleibung die Studien des Vfs. Zu Ps 15; 52 und 131 ! 
Abkürzungsverzeichnis

Vorbemerkung: Kommentare werden regelmäßig ohne Titel angeführt

\begin{tabular}{|c|c|}
\hline AASF & Annales academiae scientiarum Fennicae \\
\hline$A \cap C B$ & Anchor Bible \\
\hline ANVAO. HF & $\begin{array}{l}\text { Avhandlinger i norske videnskaps-akademi i } 0 \text { slo. } \\
\text { Historisk-filosofisk klasse }\end{array}$ \\
\hline AOAT & Alter Orient und Altes Testament \\
\hline ATD & Das Alte Testament Deutsch \\
\hline BA & Biblical archaelogist \\
\hline BC & Biblischer Commentar über das Alte Testament \\
\hline BFChTh.M & $\begin{array}{l}\text { Beiträge zur Förderung christlicher Theologie - } \\
\text { 2. Reihe: Sammlung wissenschaftlicher Monographien }\end{array}$ \\
\hline BHS & Biblia Hebraica Stuttgartensia \\
\hline $\mathrm{BiBe}$ & Biblische Beiträge \\
\hline BThSt & Biblisch-Theologische Studien \\
\hline BWANT & $\begin{array}{l}\text { Beiträge zur Wissenschaft vom Alten und Neuen } \\
\text { Testament }\end{array}$ \\
\hline BZAW & $\begin{array}{l}\text { Beihefte zur Zeitschrift für die alttestamentliche } \\
\text { Wissenschaft }\end{array}$ \\
\hline CBQ & Catholic biblical quarterly \\
\hline DJD & Discoveries in the Judaean desert of Jordan \\
\hline EB & $\begin{array}{l}\text { Die Heilige Schrift in deutscher übersetzung. } \\
\text { "Echter Bibel" }\end{array}$ \\
\hline HAT & Handbuch zum Alten Testament \\
\hline HBK & Herders Bibelkommentar \\
\hline HK & Handkommentar zum Alten Testament \\
\hline HSAT & Die Heilige Schrift des Alten Testaments \\
\hline $\operatorname{HSAT}(K)$ & $\begin{array}{l}\text { Die Heilige Schrift des Alten Testaments. Übersetzt } \\
\text { von Emil Kautzsch }\end{array}$ \\
\hline ICC & $\begin{array}{l}\text { International critical commentary on the Holy } \\
\text { Scriptures }\end{array}$ \\
\hline Int $B$ & Interpreter's bible \\
\hline JAOS & Journal of the American oriental society \\
\hline$J B L$ & Journal of biblical literature \\
\hline KAT & Kommentar zum Alten Testament \\
\hline
\end{tabular}




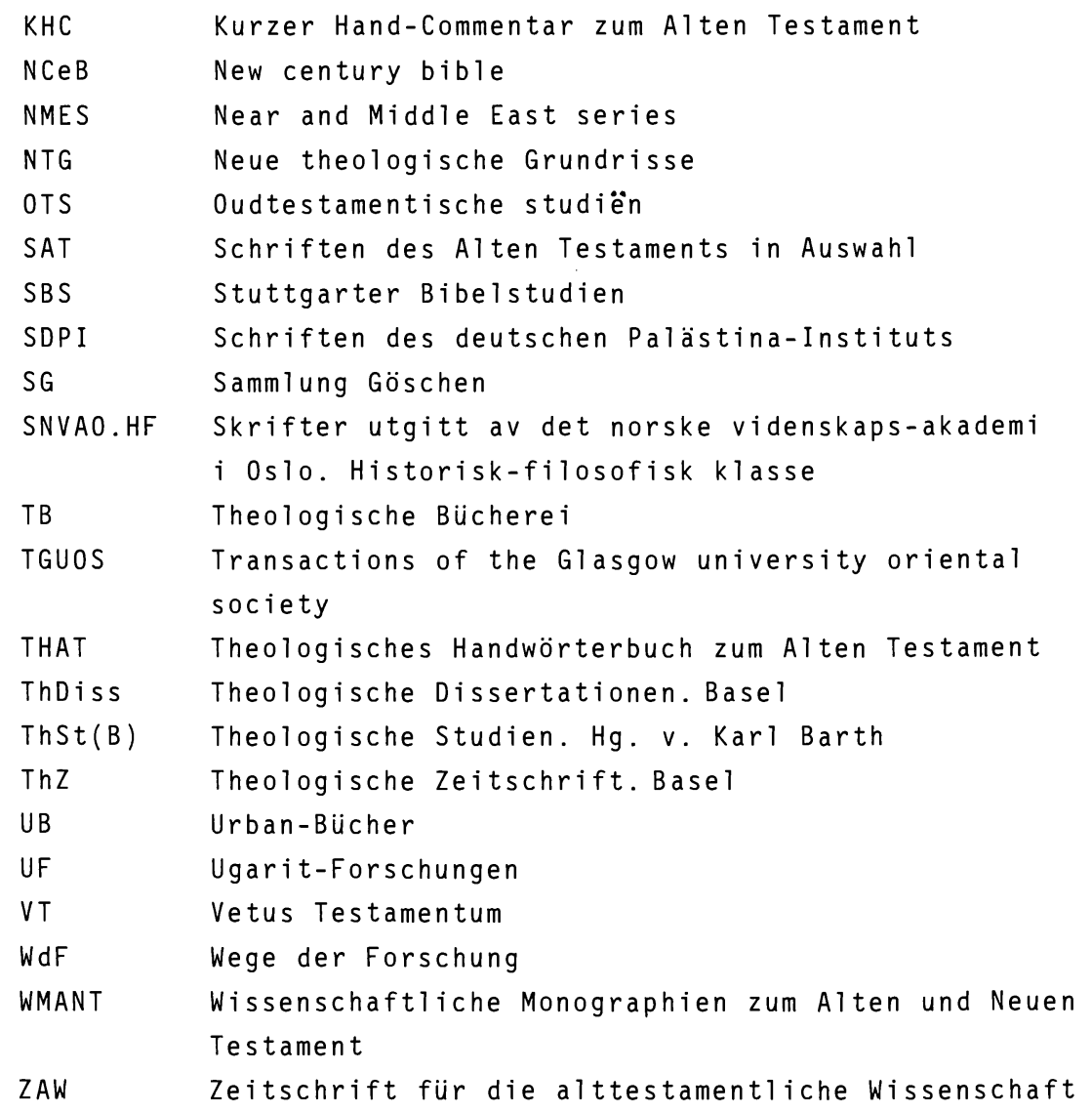


Literaturverzeichnis

ALLEGRo, J.M., Qumrân Cave 4 I (4Q158-4Q186), DJD V, 0xford 1968.

ALONSO-SCHOKEL, L., Das Alte Testament als literarisches Kunstwerk, Köln 1971.

ANDERSON, A.A., The Book of Psalms, II, NCeB, London 1972.

BAETHGEN, F., Die Psalmen, HK II 2, Göttingen ${ }^{3} 1904$.

BARTH, H. / STECK, O.H., Exegese des Alten Testaments. Leitfaden der Methodik, Neukirchen-Vluyn ${ }^{9} 1980$.

BAUMGARTNER, W. / STAMM, J.J., Hebräisches und aramäisches Lexikon zum Alten Testament, Leiden, II, ${ }^{3} 1974$; III, ${ }^{3} 1983$.

BEGRICH, J., Der Satzstil im Fünfer, in: ZIMMERLI, W. (Hrsg.), Gesammelte Studien zum Alten Testament, TB 21, München 1964, 132-167. BERTHOLET, A., Das Buch der Psalmen, HSAT(K) II, Tübingen ${ }^{4} 1923$. BEYERLIN, W., Herkunft und Geschichte der ältesten Sinaitraditionen, Tübingen 1961.

-, Werden und Wesen des 107. Psalms, BZAW 153, Berlin. New York 1979 .

-, Der 52. Psalm. Studien zu seiner Einordnung, BWANT 111, Stuttgart 1980 .

-, Wider die Hybris des Geistes. Studien zum 131. Psalm, SBS 108, Stuttgart 1982.

-, Weisheitlich-kultische Heilsordnung. Studien zum 15. Psalm, BThSt 9, Neukirchen-Vluyn 1985.

BONKAMP, B., Die Psalmen nach dem hebräischen Grundtext übersetzt, Freiburg i.Br. 1949.

BÜHLMANN, W. / SCHERER, K., Stilfiguren der Bibel, BiBe 10, Fribourg 1973.

BRIGGS, C.A. / BRIGGS, E.G., A Critical and Exegetical Commentary on the Book of Psalms, II, ICC, Edinburgh 1907.1969.

CLEMENTS, R.E., Temple and Land: A Significant Aspect of Israel's Worship, in: TGUOS 19, Glasgow 1962, 16-28.

-, God and Temple. The Idea of the Divine Presence in Ancient Israe 1, Oxford 1965 .

CULLEY, R.C., Oral Formulaic Language in the Biblical Psalms, NMES 4, Toronto 1967. 
DAHO0D, M., Psalms, III, AncB 17 A, Garden City. New York 1970.

DALMAN, G.H., Arbeit und Sitte. II. Der Ackerbau, SDPI 5, BFChTh.M 27/2, Gütersloh 1932.

-, Aramä isch-neuhebräisches Handwörterbuch zu Targum, Talmud und Midrasch, Göttingen 1938.1967.

DEISSLER, A., Die Psalmen, Düsseldorf 1964.

DELITZSCH, Franz, Biblischer Commentar über die poetischen

Bücher... Das salomonische Spruchbuch, BC IV 3, Leipzig 1873.

-, hrsg. v. DELITZSCH, Friedrich, Biblischer Kommentar über die Psalmen, BC IV 1, Leipzig ${ }^{5} 1894$.

DUHM, B., Die Psalmen, KHC XIV, Tübingen ${ }^{2} 1922$.

DURHAM, J.I., Šalôm and the Presence of God, in: DER.S. / PORTER, J.R. (Hrsg.), Proclamation and Presence, FS G.H. DAVIES, London 1970, 272-293.

EERDMANS, B.D., The Hebrew Book of Psalms, OTS IV, Leiden 1947.

ELLIGER, K. / RUDOLPH, W. (Hrsg.), Biblia Hebraica Stuttgartensia, Stuttgart $1967 / 77$.

FIELD, F. (Hrsg.), Origenis Hexaplorum quae supersunt sive veterum interpretum graecorum in totum Vetus Testamentum fragmenta, II, Oxford 1875.

FOHRER, G., über den Kurzvers, in: ZAW 66, 1954, 199-236.

-, Das Buch Hiob, KAT XVI, Gütersloh 1963.

GEMSER, B., Sprüche Salomos, HAT I 16, Tübingen ${ }^{2} 1963$.

GESE, H., Lehre und Wirklichkeit in der alten Weisheit. Studien

zu den Sprüchen Salomos und zu dem Buche Hiob, Tübingen 1958.

GESENIUS, W. / KAUTZSCH, E., Hebräische Grammatik, Leipzig 261896 .

GOLKA, F.W., Die israelitische Weisheitsschule oder "des Kaisers neue Kleider", in: VT 33, 1983, 257-270.

GOTTWALD, N.K., A Light to the Nations. An Introduction to the $01 d$ Testament, New York 1959.

GRAETZ, H., Kritischer Commentar zu den Psalmen nebst Text und Übersetzung, II, Breslau 1883.

GUNKEL, H., Einleitungen, 3. Kap., Die Propheten als Schriftsteller und Dichter, in: SCHMIDT, H., Die großen Propheten, SAT II 2, Göttingen 1915, XXXVI-LXXII.

-, Die Psalmen, HK II 2, Göttingen ${ }^{4} 1926$. 
GUNKEL, H. / BEGRICH, J., Einleitung in die Psalmen, Göttingen $1933 .^{2} 1966$.

HARAN, M., Priestertum, Tempeldienst und Gebet, in: STRECKER, G. (Hrsg.), Das Land Israel in biblischer Zeit, Göttingen 1983, $141-153$.

HAYES, J.H., The Tradition of Zion's Inviolability, in: JBL 82 , $1963,419-426$.

HERKENNE, H., Das Buch der Psalmen, HSAT V 2, Bonn 1936.

HERMISSON, H.-J., Studien zur israelitischen Spruchweisheit, WMANT 28, Neukirchen-Vluyn 1968.

HORST, F., Segen und Segenshandlungen in der Bibel, in: DERS.,

Gottes Recht. Gesammelte Studien zum Recht im Alten Testament, TB 12, München 1961.

JACOB, B., Beiträge zu einer Einleitung in die Psalmen, I, in:

ZAW 16, 1896, 129-181.

JANSEN, H.L., Die spätjüdische Psalmendichtung. Ihr Entstehungs-

kreis und ihr "Sitz im Leben", SNVAO.HF 3, 0slo 1937.

JASPER, F.N., Early Israelite Traditions and the Psalter, in:

VT $17,1967,50-59$.

JENNI, E., Das Wort Cōiäm im Alten Testament, in: ZAW 64, 1952,

$197-248 ; 65,1953,1-35$.

JOHNSON, A.R., Sacral Kingship in Ancient Israel, Cardiff ${ }^{2} 1967$. KALT, E., Die Psalmen, HBK VI, Freiburg i.Br. 1935.

KAYSER, W., Das sprachliche Kunstwerk. Eine Einführung in die

Literaturwissenschaft, Bern. München ${ }^{17} 1976$.

KEET, C.C., A Study of the Psalms of Ascents. A Critical and

Exegetical Commentary upon Ps CXX to CXXXIV, London 1969.

KOCH, K., Gibt es ein Vergeltungsdogma im Alten Testament?, in:

DERS. (Hrsg.), Um das Prinzip der Vergeltung in Religion und

Recht des Alten Testaments, WdF 125, Darmstadt 1972, 130-180.

-, Die Profeten. II. Babylonisch-persische Zeit, UB 280, Stutt-

gart 1980.

KONIG, E., Stilistik, Rhetorik, Poetik in Bezug auf die bibli-

sche Litteratur komparativisch dargestellt, Leipzig 1900.

KRAUS, H.-J., Psalmen, I.II, BK XV 1.2, Neukirchen-Viuyn ${ }^{5} 1978$.

KUGEL, J.L., The Idea of Biblical Poetry. Parallelism and its

History, New Haven.London 1981. 
KUNTZ, J.K., The Canonical Wisdom Psalms of Ancient Israel:

Their Rhetorical, Thematic, and Formal Dimensions, in:

Rhetorical Criticism. FS J. MUILENBURG, Pittsburgh Theo-

logical Monograph Series I, Pittsburgh 1974, 186-222.

LAUHA, A., Die Geschichtsmotive in den alttestamentlichen

Psalmen, AASF LVI 1, Helsinki 1945.

LAUSBERG, H., Elemente der literarischen Rhetorik, München 81984 .

LEEUW, G. van der, Phänomenologie der Religion, NTG, Tübingen

21956 .

LEEUWEN, C. van, Art. řsc in: JENNI, E. / WESTERMANN, C.

(Hrsg.), THAT II, München 1976.

LEMAIRE, A., Sagesse et écoles, in: VT 34, 1984, 270-281.

LESLIE, E.A., The Psalms. Translated and Interpreted in the

Light of Hebrew Life and Worship, Nashville.New York 1949.

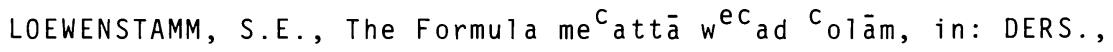

Comparative Studies in Biblical and Ancient Oriental Litera-

tures, AOAT 204, Neukirchen-Vluyn 1980, 166-170.

LORETZ, 0., Die Psalmen, II, Beitrag der Ugarit-Texte zum Ver-

ständnis von Kolometrie und Textologie der Psalmen. Ps 90-

150, AOAT 207/2, Neukirchen-Vluyn 1979.

MANDELKERN, S., Veteris Testamenti Concordantiae Hebraicae atque

Chaldaicae, I, Neudruck Graz 21955.

MANNATI, M. / SOLMS, E. de, Les Psaumes, IV, Paris 1968.

METZGER, M., Himmlische und irdische Wohnstatt Jahwes, in: UF 2, Neukirchen-Vluyn 1970, 139-158.

MEYER, R., Hebräische Grammatik, SG, Berlin, I 31966; II ${ }^{3} 1969$; I I I 3972 .

MOWINCKEL, S., Religion und Kultus, Göttingen 1953.

-, Real and Apparent Tricola in Hebrew Psalm Poetry, ANVAO.HF II, $0 s 101957, \mathrm{Nr} .2$.

MURPHY, R.E., Assumptions and Problems in $01 d$ Testament Wisdom

Research, in: CBQ 24, 1967, 407-418.

NÖTSCHER, F., Die Psalmen, EB, Würzburg ${ }^{5} 1959$.

OESTERLEY, W.O.E., The Psalms. Translated with Text-critical and

Exegetical Notes, London 1939.1959. 
PETERSEN, D.L., Late Israelite Prophecy. Studies in DeuteroProphetic Literature and in Chronicles, Society of Biblical Literature: Monograph Series XXIII, Missoula.Montana 1977. PLOEG, J.P.M. van der, Psalmen, II, De Boeken van het oude Testament VII B, Roermond 1974.

PLOGER, 0., Sprüche Salomos. Proverbia, BK XVII, NeukirchenVluyn 1984.

PORTEOUS, N.W., Jerusalem-Zion: the Growth of a Symbol, in: Verbannung und Heimkehr, FS W. RUDOLPH, Tübingen 1961, neuabgedruckt in: Living the Mystery, Oxford 1967, 93-111.

PRESS, R., Der zeitgeschichtliche Hintergrund der Wallfahrtspsalmen, ThZ 14, 1958, 401-415.

RAD, G. von, Weisheit in Israel, Neukirchen-Vluyn 1970.

RAHLFS, A. (Hrsg.), Septuaginta, II, Stuttgart 1949.

REVENTLOW, H. Graf, Friedensverheißungen im Alten und Neuen Testament, in: Friede über Israel. Zeitschrift für Kirche und Judentum, Hannover (3) 1979, 99-109.147-153.

RIDDERBOS, N.H., Die Psalmen. Stilistische Verfahren und Aufbau ..., BZAW 117, Berlin. New York 1972.

ROHLAND, E., Die Bedeutung der Erwählungstraditionen Israels für die Eschatologie der alttestamentlichen Propheten, Diss. Heidelberg 1956.

SANDERS, J.A., The Psalms Scroll of Qumrân Cave 11, DJD IV, $0 \times$ ford 1965 .

SCHMIDT, H., Die Psalmen, HAT I 15, Tübingen 1934.

SCOTT, R.B.Y., The Way of Wisdom in the $01 d$ Testament, New York 1971 .

SEGERT, S., Parallelism in Ugaritic Poetry, in: JAOS 103, 1983, 295-306.

SEIDEL, H., Wallfahrtslieder, in: DERS. / BIERITZ, K.H. (Hrsg.),

Das lebendige Wort. Beiträge zur kirchlichen Verkündigung.

Festgabe für G. VOIGT zum 65. Geburtstag, Berlin 1982, 26-40. SEYBOLD, K., Der a aronitische Segen. Studien zu Numeri 6,22-27, Neukirchen-Vluyn 1977.

-, Die Wallfahrtspsalmen, BThSt 3, Neukirchen-Vluyn 1978.

-, Die Redaktion der Wallfahrtspsalmen, in: ZAW 91, 1979, 247 268.

STAERK, W., Lyrik, SAT III 1, Göttingen ${ }^{2} 1920$. 
STECK, O.H., Friedensvorstellungen im alten Jerusalem. Psalmen, Jesaja, Deuterojesaja, ThSt(B) 111, Zürich 1972.

-, Strömungen theologischer Tradition im Alten Israel, in: DERS., Wahrnehmungen Gottes im Alten Testament, TB 70, München 1982 , 291-317.

STOLZ, F., Strukturen und Figuren im Kult von Jerusalem. Studien zur altorientalischen, vor- und frühisraelitischen Religion, BZAW 118 , Berlin 1970.

-, Psalmen im nachkultischen Raum, ThSt(B) 129, Zürich 1983. SWETE, H.B. (Hrsg.), The $01 d$ Testament in Greek. According to the Septuagint, II, Cambridge ${ }^{3} 1907$.

TAYLOR, W.R., Psalms, IntB 4, New York.Nashville 1955.

VAUX, R. de, Das Alte Testament und seine Lebensordnungen, I, Freiburg.Basel.Wien 1960.1962.

VONCK, P., L'expression de confiance dans le Psautier, in:

Message et Mission, Publications de l'Université Lovanium de Kinshasa 1968, 1-51.

WALTER, D.M. (Bearb.), Liber Psalmorum, in: The Peshitta Institute Leiden (Hrsg.), Vetus Testamentum Syriace II 3 , Leiden 1980.

WALTON, B. (Hrsg.), Biblia Sacra Polyglotta, III, Nachdruck Graz 1964.

WEBER, R. (Hrsg.), Biblia sacra iuxta vulgatam versionem, I, Stuttgart 1969.

WEHMEIER, G., Der Segen im Alten Testament. Eine semasiologische Untersuchung der Wurzel brk, ThDiss VI, Basel 1970.

WEISER, A., Die Psalmen, ATD 14/15, Göttingen ${ }^{8} 1973$.

WESTERMANN, C., Der Segen in der Bibel und im Handeln der

Kirche, München 1968.

WHYBRAY, R.N., The Intellectual Tradition in the $01 d$ Testament, BZAW 135, Berlin. New York 1974.

WILDBERGER, H., Jesaja, III, BK X 3, Neukirchen-V1uyn 1982. WOLFF, H.W., Dodekapropheton. IV. Micha, BK XIV 4, NeukirchenVluyn 1982.

WRIGHT, G.E., The Significance of the Temple in the Ancient Near

East. III. The Temple in Palestine-Syria, in: BA 7, 1944, 66-77. WURTHWEIN, E., Der Text des Alten Testaments, Stuttgart ${ }^{4} 1973$. WUTZ, F., Die Psalmen. Textkritisch untersucht, München 1925. 
Bibelstellenregister

Gen

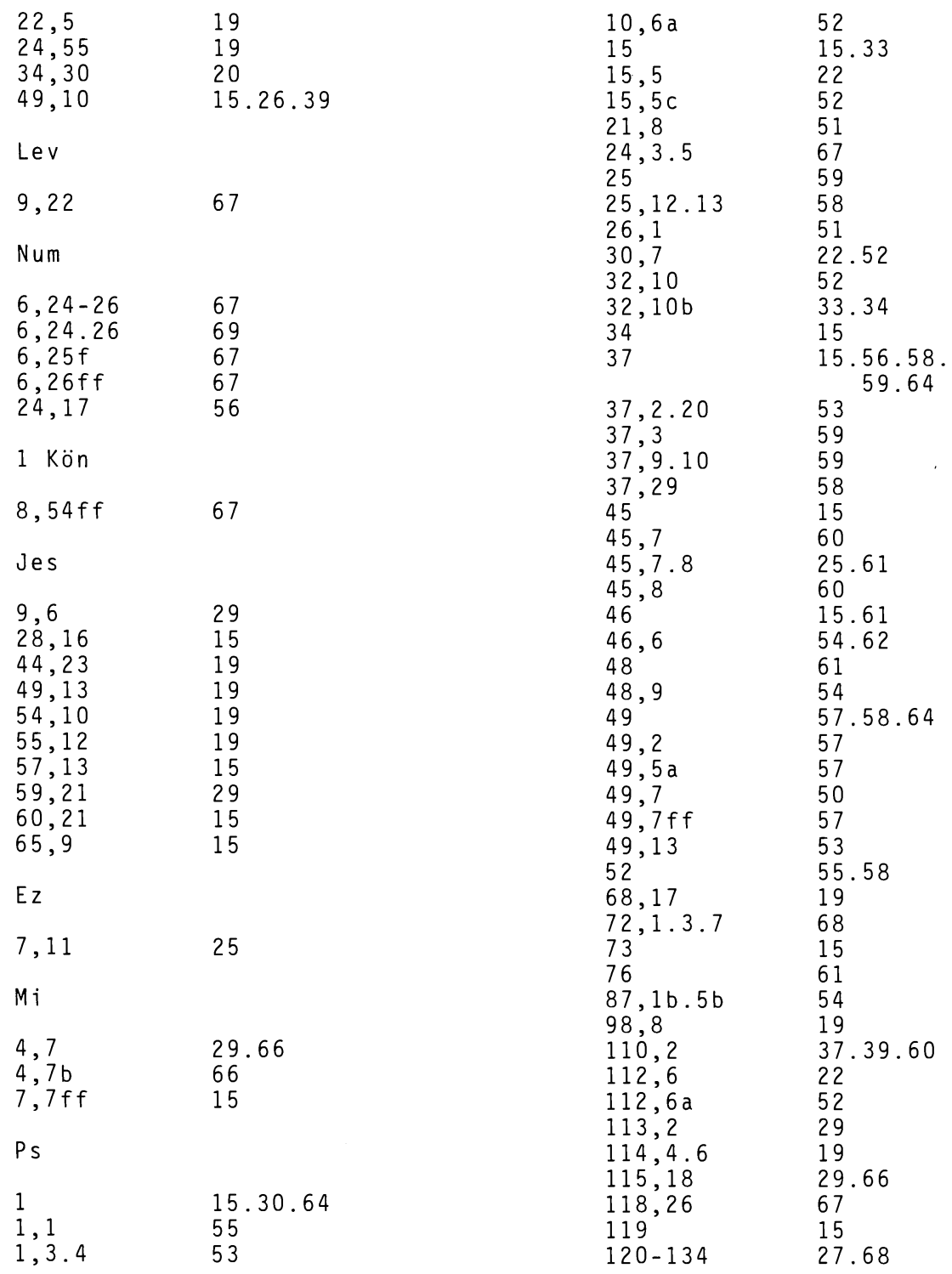




$\begin{array}{ll}121,7.8 & 69 \\ 121,8 & 29.66 \\ 122,6-8 & 68 \\ 127,4 & 53 \\ 128,5.6 & 67 \\ 128,6 b & 43 \\ 131,2 & 53 \\ 131,3 & 29.64 \\ 134,3 & 67\end{array}$

Spr

$1,10-19 \quad 55$

2, $13 \mathrm{ff} \quad 15$

4,14-19 55

$10,9 \quad 53$

$10,26 \quad 53$

$10,30 \quad 22$

$10,30 \mathrm{a} \quad 52$

$11,22 \quad 53$

11,28 50.51

$12,4.18 \quad 53$

$13,20 \quad 55$

$15,19 \quad 53$

$16,12 \mathrm{ff} \quad 60$

$16,20 \quad 50.51$

$24,1 \quad 55$

$25,11-14.18-20.53$

$23-26.28$

26

27

53

28,18

53

28,25

28,26

53

50.51

50.51

29,25

50.51

I job

31,2

59

$1 \mathrm{Chr}$

17,27

69

Sir

32,23 